Nineteenth-Century Music Review, page 1 of 31 (C) The Author(s), 2020. Published by Cambridge University Press. This is an Open Access article, distributed under the terms of the Creative Commons Attribution licence (http:/ / creativecommons.org/licenses/by/4.0/), which permits unrestricted re-use, distribution, and reproduction in any medium, provided the original work is properly cited.

doi:10.1017/S1479409819000673

\title{
Digital Editions and the Creative Work of the Performer
}

\author{
John Rink \\ University of Cambridge \\ jsr50@cam.ac.uk
}

\begin{abstract}
One of the aims of this article is to clarify and align more closely the respective priorities of researchers and practical musicians in using music notation. To that end, the first part surveys existing digital editions of music both in general and from the standpoints of different types of performer. Consideration is then given to a new 'digital edition concept' which might achieve more creative engagement with music on the parts of instrumentalists and singers alike. Two ostensibly conventional editions of nineteenth-century music serve as the basis of case studies that show how the notorious limitations of the printed page might be transcended more effectively and propitiously. The conclusion is that digital editions of music (DEMs) are unlikely to replace printed editions and that wholesale replacement should not be the goal in any case. Instead, in developing future DEMs for performers, the aim should be to take fuller advantage of the affordances of the digital medium so that musicians can engage with and make music all the more creatively. Only by moving conceptually beyond the stasis of 'the material medium' and harnessing the dynamic flux of the digital medium can the dynamic flux inherent in music itself best be captured. At the same time, it is important to recognize and respect musicians' need for a fixed version of the score on given performance occasions, even if it is bound to be superseded thereafter.
\end{abstract}

Even a cursory glance at Stanford's 'Digital Resources for Musicology', Princeton's 'Guide to Online Music Sources' or similar websites reveals the existence of a huge number of digital scores ranging from manuscripts and early imprints to contemporary art music and jazz, intended for a commensurately broad spectrum of users. ${ }^{1}$ This article evaluates current digital editions of music in terms of their value to performers in particular, and in doing so it seeks to clarify and, to some extent, align more closely the respective priorities of researchers on the one hand and practical musicians on the other. To that end, the first part of the article surveys a selection of digital editions both in general and from the standpoints of different types of performer. I then encourage the development of a 'digital edition concept' with the potential to effect more creative engagement with music on the parts of instrumentalists and singers alike. Two ostensibly conventional editions of nineteenth-century music serve as case studies demonstrating how the notorious limitations of the printed page might be transcended more effectively and propitiously.

$$
* * *
$$

1 Respectively, https://drm.ccarh.org and https://libguides.princeton.edu/digitalscores. All of the online materials cited in this article were accessed on 10 January 2020. 
On the face of it, digital editions of music (hereafter DEMs) have come a long way since 2009, when Frans Wiering lamented an 'almost complete' lack of attention within musicology to 'more radical possibilities for innovation' beyond 'currently accepted practices such as the use of music notation software for the preparation of scores, the online distribution of music in PDF format or even the interchange of score data in some encoded format'. He speculated that this regrettable state of affairs could be variably attributed to musicologists' disappointment with information and communications technology after 'so many failed promises', a lack of maturity in the available technology, and a perception that DEMs were of 'limited use'. ${ }^{2}$ George Litterst struck a more positive note a year later when outlining the practical benefits of digital sheet music, including 'the ability to replace an entire room full of print materials with a single, handheld device'; search, highlighting and annotation features; ease of access; control over the size of text; copy-and-paste functionality; enhanced readability in low light; hands-free reading; and 'audio-interpretation of the text'. ${ }^{3}$

Despite the potential advantages of digital formats, what might be called a 'print to play' tendency remains widespread, partly because the online distribution of music in the form of PDF files continues in large part to define how musicians engage with digital scores. In discussing four different types of digital edition scholarly edition, e-score database, downloadable files of a self-publishing composer, and a vendor's self-publishing service - Lisa Hooper noted in 2013 the propensity of users to print the material for practical purposes, 'utterly defeating the original intent' by 'taking the " $\mathrm{e}$ " out of e-score'. 4 The implications of this lingering tendency will be assessed later.

In the survey of existing DEMs that follows here, four broad categories different from those posited by Hooper are considered in turn:

1. 'plain' scores available in PDF or similar formats;

2. digital scores expressly enhanced for performers;

3. 'dynamic editions' of a scholarly nature; and

4. other initiatives which problematically lay claim to the status of DEM.

Available in diverse online resources, some of the 'plain' scores in the first category are born-digital, although a larger proportion consists of digitized versions of printed editions. For all intents and purposes, these scores amount to print surrogates, or at least close counterparts of printed scores. The dates and provenance of the underlying editions typically determine whether the digital versions are free of charge or commercially disseminated. One example of the former is the crowdsourced Petrucci Music Library, or IMSLP (International Music Score Library Project) ${ }^{5}$ comprising approximately 500,000 scores and over 59,000 recordings which are either out of copyright or available under Creative Commons licences.

2 Frans Wiering, 'Digital Critical Editions of Music: A Multidimensional Model', in Modern Methods for Musicology: Prospects, Proposals and Realities, ed. Tim Crawford and Lorna Gibson (London: Ashgate, 2009): 23.

3 George Litterst, 'Random Access: A Ringside Seat', American Music Teacher 60/3 (2010-11): 50.

4 Lisa Hooper, 'Contemplating E-Scores: Open Ruminations on the E-Score, the Patron, the Library, and the Publisher', in Proceedings of the Charleston Library Conference (West Lafayette, IN: Purdue University, 2013): 572; http://dx.doi.org/10.5703/1288284315326.

5 https://imslp.org. 
This impressive and widely used resource is a first port of call for many musicians wanting easily accessible, free material. So too is ChoralWiki, which similarly hosts c. 33,500 free scores of choral/vocal works plus texts and translations in the Choral Public Domain Library (CPDL). ${ }^{6}$ Another large but more specialized resource is the Lester S. Levy Sheet Music Collection, whose c. 30,000 scores dating from 1780 to 1980 concentrate in particular on nineteenth-century American popular music. ${ }^{7}$ In addition to downloadable PDFs, this resource provides a Performance View button below each sheet music image yielding a full-screen view of the score; the use of arrow keys, tapping or finger-swiping allows musicians to 'turn pages' while performing, although at present there is no other performancespecific functionality.

The Levy collection is also designed for scholarly purposes, as is the Web Library of Seventeenth-Century Music, which offers modern editions (with parts in some cases) of commercially unavailable instrumental and vocal music, including instrumental trios, keyboard pieces, solo cantatas, masses and other large liturgical works. ${ }^{8}$ For these rigorously prepared editions, which are intended for performers as well as scholars, there are introductions and critical reports like those in print editions, along with sound files posted as streaming video. Another free scholarly resource is the NMA Online, which presents a digitized version of the musical text and critical commentaries of the entire Neue Mozart-Ausgabe. ${ }^{9}$ Finally, in the commercial sphere, A-R Editions, which was founded in 1962 as a publisher of scholarly critical editions, markets 'digital print music' by various composers for study or performance, the purchase of which 'allows unlimited viewing and printing through a browser interface, both immediately and in the future'.

Although a critical apparatus is available in the latter two cases, most resources in this first category include no such material, nor is there much if any new editorial overlay targeted specifically at performers. Moreover, only the Levy collection has digital tools designed for performance purposes. In contrast, the second category of DEMs reviewed here consists of digital scores enhanced for performers by means of added functionality, the provision of diverse types of explanatory material (whether audio, video or text-based), or both. Two examples - Henle Library ${ }^{11}$ and Peters Masterworks ${ }^{12}$ - are based on print editions with a firm foothold in the commercial marketplace. The Henle Library app combines 'reliable Urtext with the latest technology', allowing musicians to have 'tried-and-tested editions' on their tablets, adjust the layout in certain ways and use a metronome tool (see Fig. 1a), choose or insert fingerings (Fig. 1b), add other annotations (Fig. 1c), see 'score comments' - i.e. editorial notes from a conventional critical commentary - in pop-ups attached to individual bars (Fig. 1d), and so forth. Available in multiple languages,

6 www.cpdl.org/wiki.

https://levysheetmusic.mse.jhu.edu.

www.sscm-wlscm.org.

https://dme.mozarteum.at/nmaonline.

10 www.areditions.com/publications/digital-prints.html.

11 www.henle-library.com. The Henle Library includes a vast number of works from the eighteenth through twentieth centuries for chamber ensembles and solo keyboard, strings, winds and other instruments. For some, multiple fingerings are offered but, at present, no recordings. Compare nkoda (www.nkoda.com), which markets DEMs of other publishers' output.

12 www.editionpeters.com/newsdetails.php?articleID=IN01132. 


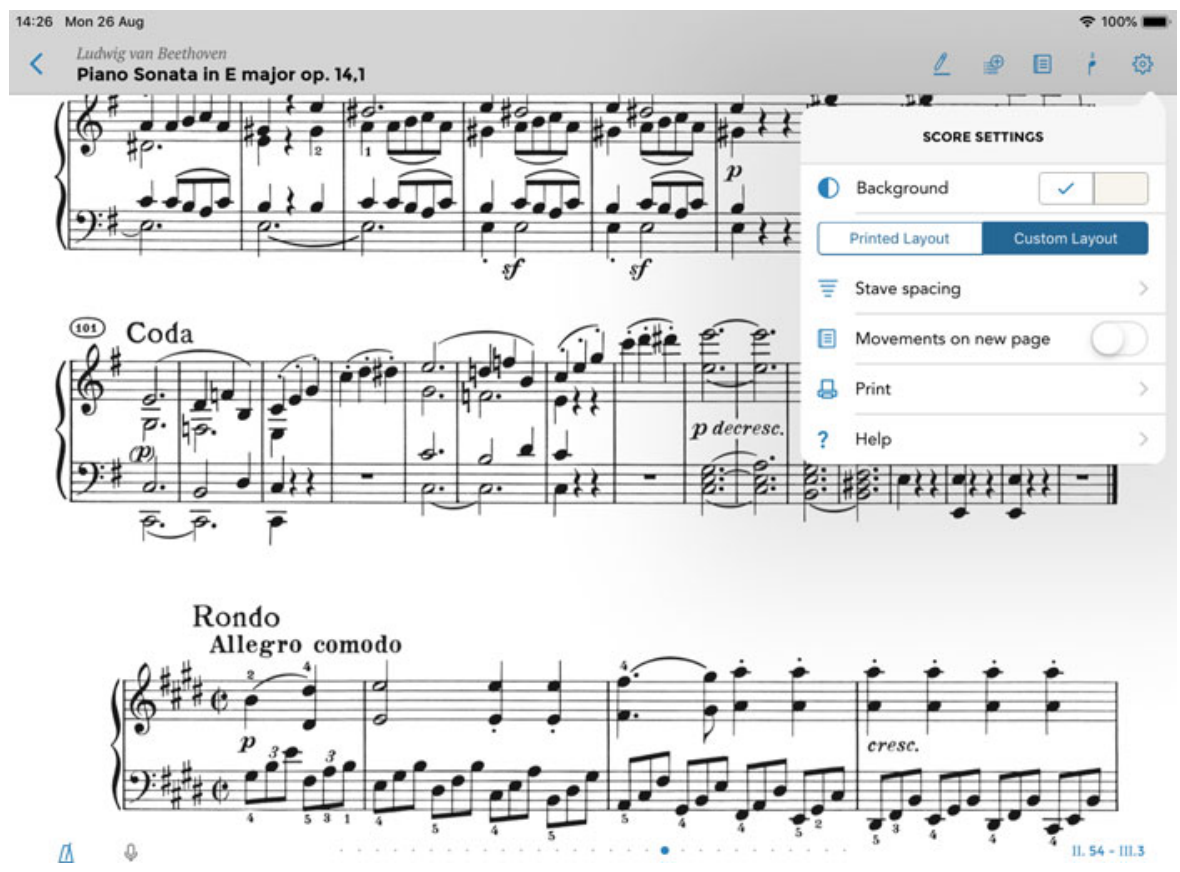

Fig. 1a Henle Library app - layout options, metronome and recording tools, etc.: Beethoven, Sonata in E major Op. 14 No. 1, ii: 54-62, 101-116; iii: 0-3

the Henle app is targeted at professional musicians, students and teachers. The 'high-quality interactive scores' in the Piano Masterworks series have similar practical features, but in some cases there are also 'video performances and masterclasses, studio recordings aligned to the notation, automatic page-turning, and exclusive expert commentaries'. ${ }^{13}$ These 'digitally enriched editions of core piano repertoire' - which are not as interactive as their description suggests are accessed via the Tido Music app for iPads and desktop browsers (Fig. 2), ${ }^{14}$ which, among other things, features a scroll-through highlighter indicating one's location in the music as it is played. A comparable tool is available on the carus music choir app, which presents 'carefully prepared Urtext music editions' synchronized with recordings by 'renowned interpreters' while offering 'innovative features for choral singers and musicians' to assist with 'effective rehearsal preparation'. ${ }^{15}$ Navigation is meant to be intuitive, page-turning can be automatic or

13 www.editionpeters.com/newsdetails.php?articleID=IN01132.

$14 \mathrm{http}$ ///tidomusicapp.com; for further information see the early review at https:// crosseyedpianist.com/2016/09/12/your-own-private-masterclass-tido-music-app. See www.tido-music.com/home for details of the Piano Masterworks series (which extends from J.S. Bach to John Cage and other mid- to late-twentieth-century composers, as well as jazz and blues) and of Tido's other piano and vocal collections, featured artists (e.g. Lang Lang), etc. The available 'pro recordings' vary in terms of the nature of production (i.e. public versus tailormade for Tido), instrument (piano, voice and piano, piano accompaniment only), etc.

\footnotetext{
15 www.carus-verlag.com/en/digital-media/carus-music-the-choir-app.
} 


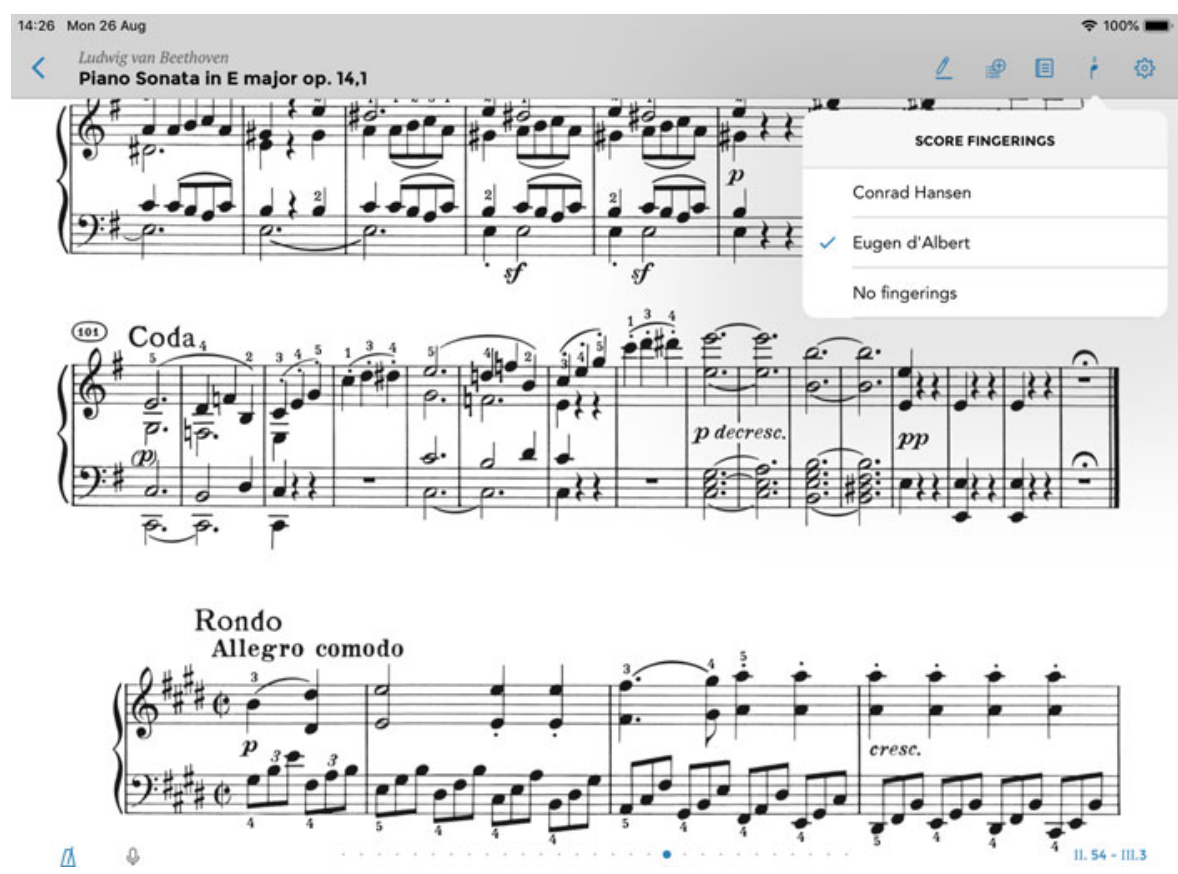

Fig. 1b Henle Library app - fingering options: Beethoven, Sonata in E major Op. 14 No. 1, ii: 54-62, 101-116; iii: 0-3

manual, and there is a 'coach' to help individual choral singers learn their parts. The carus app is 'optimised for mobile devices (tablets and smartphones)'.

Along similar lines, while also anticipating the next category in this survey, Gustaf - a digital sheet music reader which was fully operational when this essay was first drafted in October 2018 but which largely disappeared during the ensuing ten months - set out to market 'thousands of scores' in diverse idioms in collaboration 'with the biggest publishers in the world'. ${ }^{16}$ Among other things, users of the app or online version were able to read, play, annotate and edit sheet music - including scores that they uploaded themselves - in addition to transposing pieces if they wished (although glaring errors occurred in the experiments that I tried). Unlike the digital scores discussed thus far, which typically use PDF, TIFF, svg and other image-based formats, Gustaf operated with MusicXML files, adapting them 'to display and play on different devices that can run HTML5 software'; PDF files were also supported although 'with less interactivity'. ${ }^{17}$ The standard of the engraving was variable and less than ideal, likewise the functionality of the app and online interface; furthermore, the fact that Gustaf was not restricted to 'reliable Urtext' or similar high-quality editions had significant implications for the standard of the content. Despite

16 Previously the full Gustaf site was available at https: / /www.gogustaf.com, but both it and the score app (which as recently as August 2019 could be accessed at https: / app.gogustaf.com) now lack their original functionality; moreover, the Gustaf Twitter account has been silent since 2017. I am grateful to Raffaele Viglianti for alerting me to the app version.

17 www.musicxml.com/software. 


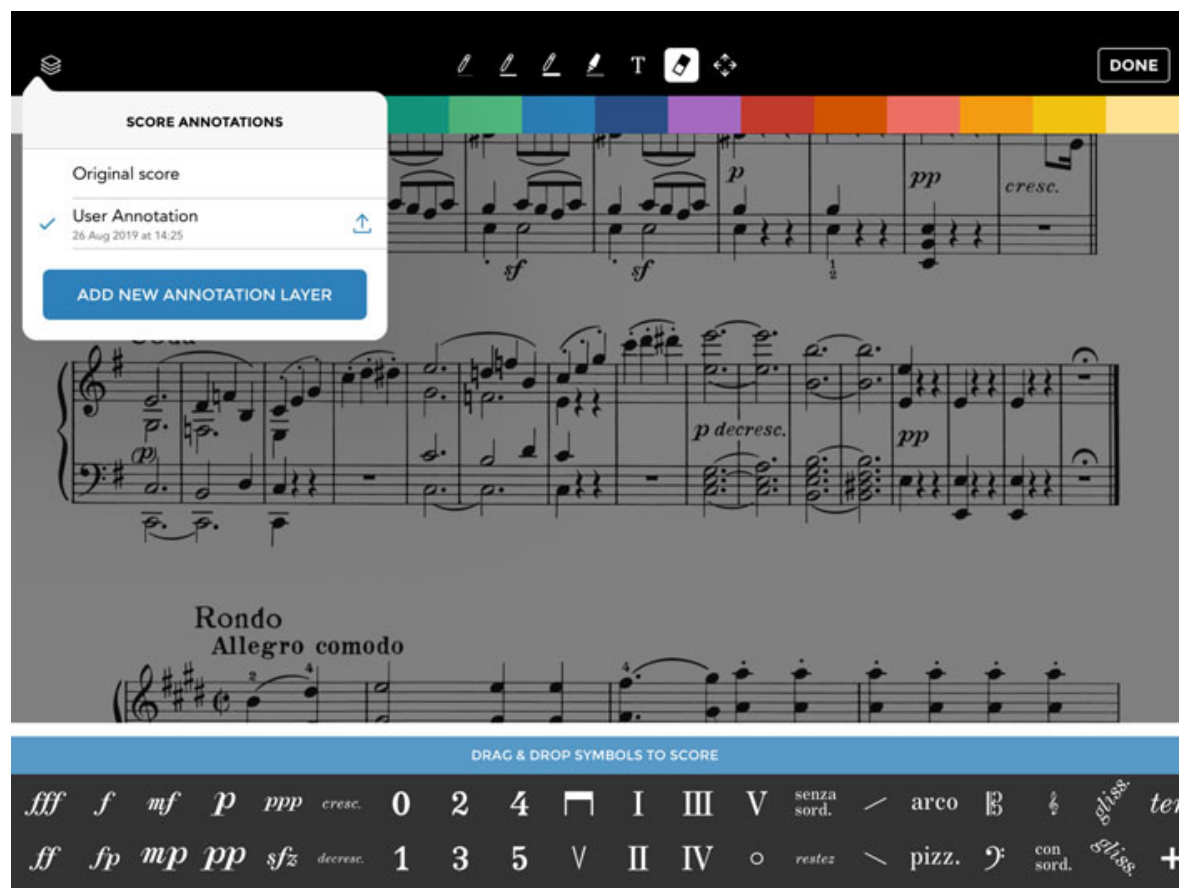

Fig. 1c Henle Library app - annotation options: Beethoven, Sonata in E major Op. 14 No. 1, ii: 54-62, 101-116; iii: 0-3

these shortcomings, Gustaf had greater interactive possibilities than the other products reviewed so far and therefore came closer to a truly digital edition of music. $^{18}$

'Dynamic' scholarly editions - the third category under review - include the Lost Voices Project (Fig. 3), in which MEI-compliant encodings enable users not only to compare variants but to choose among them for the sake of reconstruction and style analysis. ${ }^{19}$ In addition, there are facsimiles and modern transcriptions of textual material, along with scholarly commentaries, additional research tools and links to related projects. All of this is meant to encourage performers among others 'to explore the rich world of the chanson at mid [sixteenth] century' ${ }^{20}$ To call this a 'performing edition' first and foremost would not be accurate, however, nor would

18 Compare Gustaf to Newzik (https://newzik.com), a digital sheet music reader for iPad 'tailored to meeting the unique needs of professional orchestras'. Although it is not a DEM, the cloud-based app lets users import material in diverse formats, including PDF music, MusicXML scores, and audio and video files. According to the distributors, the 'true power of Newzik lies within its collaborative features', which enable members of ensembles 'to share their markings or any edits in real-time'. Hands-free page-turning is possible by using a Bluetooth foot pedal.

19 http://digitalduchemin.org. MEI is the standard identifier both for the Music Encoding Initiative and for the coding system developed as part of that project. For information see http://music-encoding.org.

20 http://digitalduchemin.org/about. 

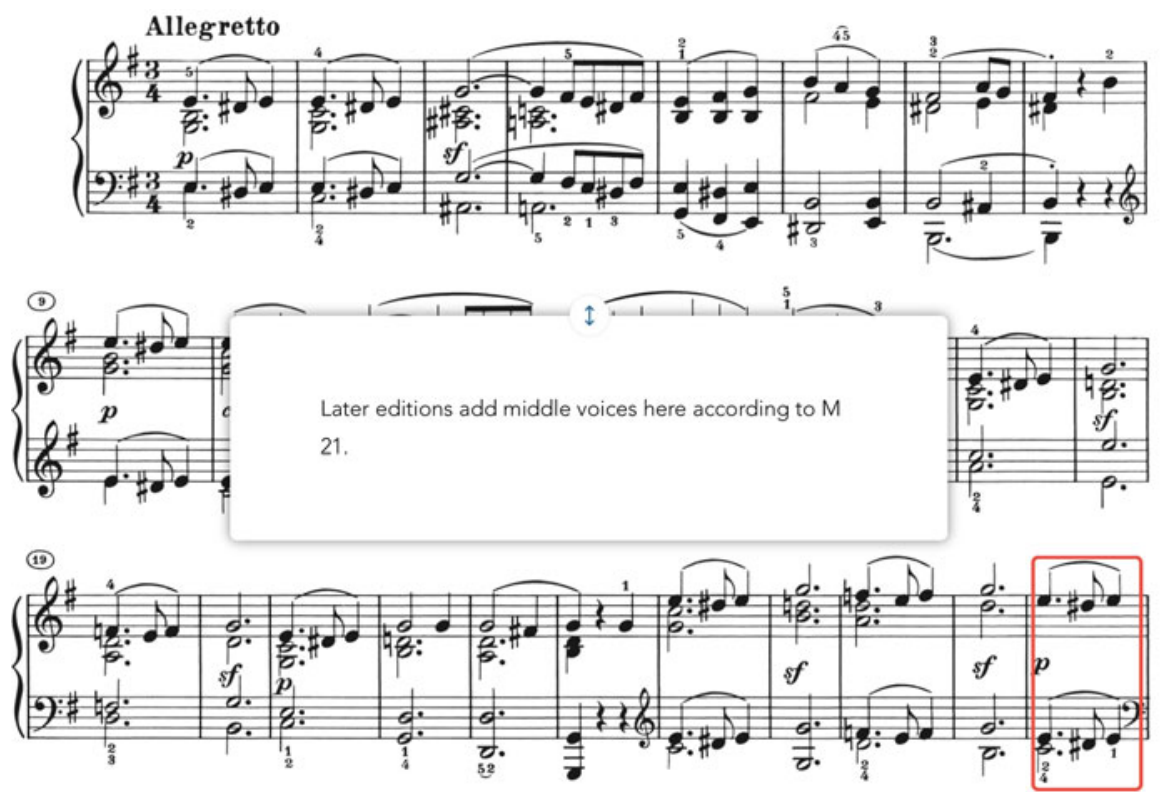

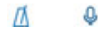

Fig. 1d Henle Library app - pop-up comment to final bar in the excerpt, referring to the voicing in bar 21 (i.e. 'M 21'): Beethoven, Sonata in E major Op. 14 No. 1, ii: 1-29

such a description apply to the Computerized Music Mensural Editing project (CMME; Fig. 4), ${ }^{21}$ which constitutes an 'experimental database of online early music editions' presenting 'virtual scores of 14th-16th century compositions which can be tailored to the needs of individual users'. ${ }^{22}$ CMME's goal has been an 'entirely new form of critical music edition in which dynamically generated, user-configured formats remove the unwieldiness of multiple printed editions, replacing it with the concept of multiple states of a single edition' ${ }^{23}$ However laudable its aims, the project has managed to produce only a small amount of material, and what does exist has little scope for interactivity as far as I can determine, perhaps because the CMME website is not kept up to date. Furthermore, the digital resource is based on a unique 'encoding dialect', ${ }^{24}$ with commensurately limited potential for interoperability.

A different mode of interaction is facilitated by the Online Chopin Variorum Edition project (OCVE; Fig. 5), which I have directed since its inception in

21 www.cmme.org.

22 The latter text appears on Google when a search on CMME is conducted.

23 www.cmme.org/about.

24 Marnix van Berchum, 'The Future is Now - Editing Josquin in a Digital World', paper presented 31 August 2018, Utrecht, Netherlands, at a symposium on 'Editing the Past', sponsored by Royal Society for Music History of the Netherlands (KVNM), Foundation for Historical Performance Practice (STIMU) and Utrecht Early Music Festival. 


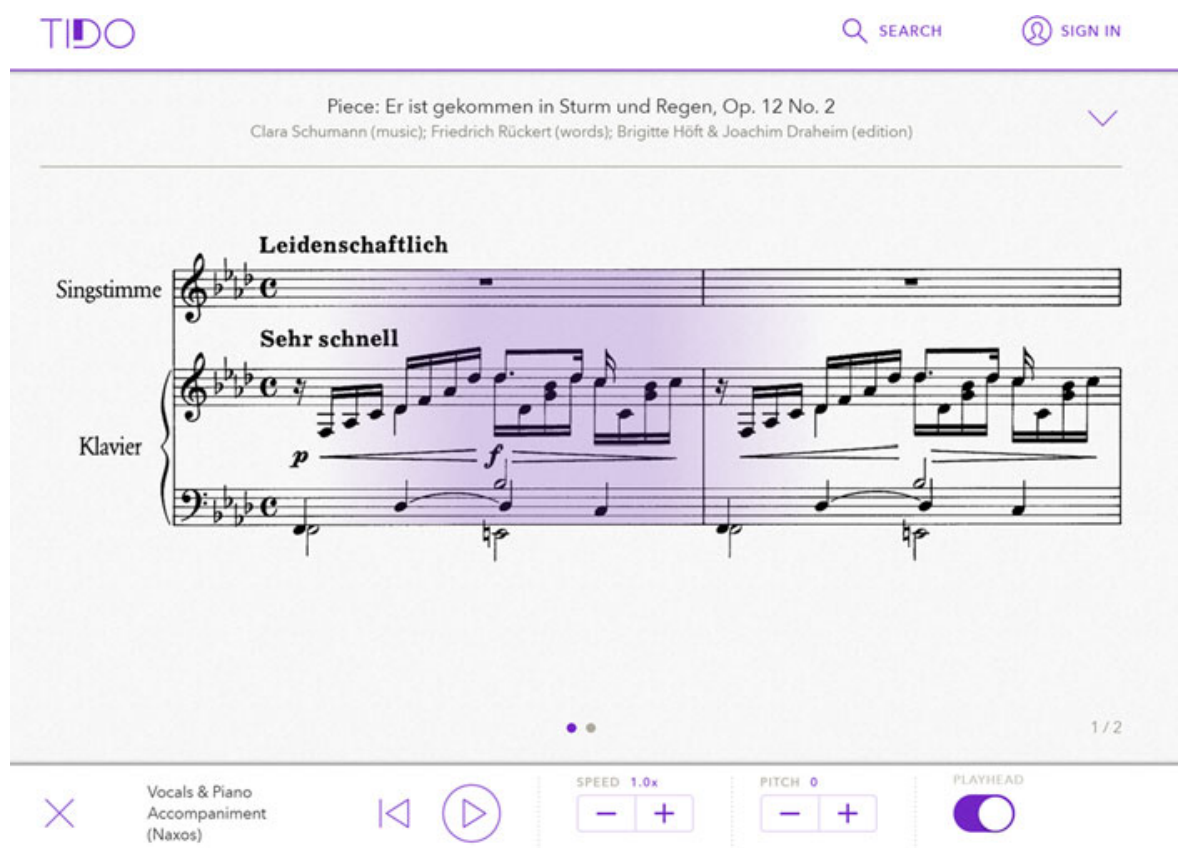

Fig. 2 Tido app, showing locator tool: Clara Schumann, 'Er ist gekommen in Sturm und Regen' Op. 12 No. 2, bars 1-2 (www.tido-music.com/pieces/e640e395-5b71-44068346-cffea 4 b37db5)

2003. ${ }^{25}$ OCVE provides digital images of the manuscripts and first editions of most of the solo piano music by Fryderyk Chopin, along with simple-to-use tools that allow one to compare corresponding passages in discrete witnesses and thereby to trace the music's creative history from the earliest notated artefacts through to revised impressions of the original prints. Users have access to background information and indicative 'critical commentaries' generated by the project team, with the capacity to add public or private annotations of their own. The understanding that OCVE fosters through intertextual, interstitial reading of the constituent sources is the basis of the virtual 'edition' alluded to in the title of the project.

This notion of the 'edition in flux' may have its merits, not least in challenging and redefining the nineteenth-century work concept, but, once again, there are practical limitations, among them the fact that nothing tangible for use in performance results from the digital interactivity that OCVE promotes. Ironically, in attempting to transcend the conventional view of an edition as 'a text (i.e., a unique arrangement of symbols) established by an agent (an editor) to represent a work for some specific public purpose ... or for some specific class of users', ${ }^{26}$ OCVE has less practical utility in the context of performance than a standard score would, whether in print or

25 www.chopinonline.ac.uk/ocve; for a review, see Alison Hood, 'Review Article: Chopin Online', Nineteenth-Century Music Review 14 (2017): 159-74. OCVE was funded by the Andrew W. Mellon Foundation from 2003 to 2017 in a series of five grants.

26 Ronald Broude, 'Musical Works, Musical Texts, and Musical Editions: A Brief Overview', Scholarly Editing: The Annual of the Association for Documentary Editing 33 (2012): 16. 


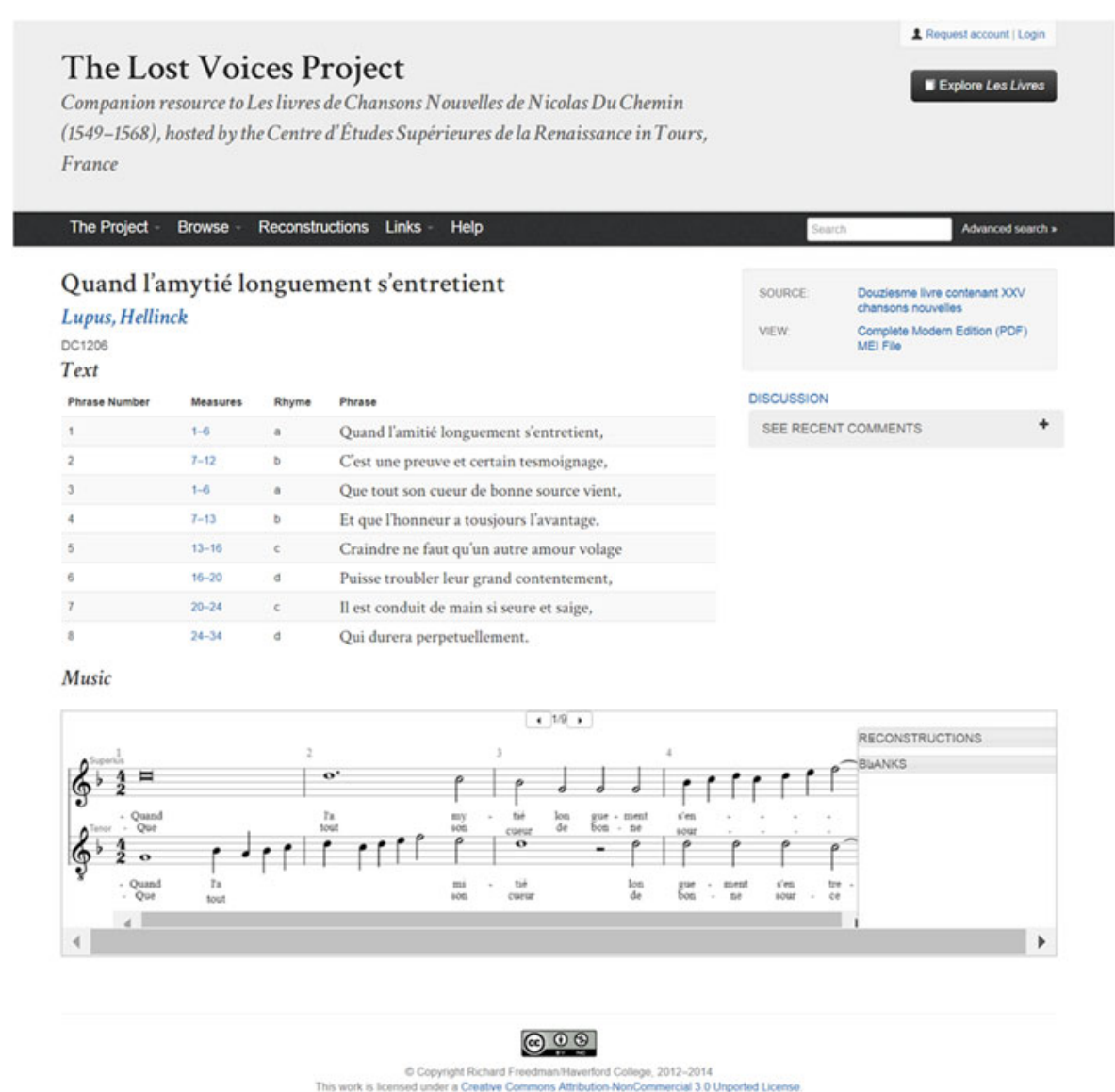

Fig. 3 Du Chemin Lost Voices Project: Lupus Hellinck, ‘Quand l'amytié longuement s'entretient', bars 1-4 (http://digitalduchemin.org/piece/DC1206)

digital form. This is because, as yet, the project has not realized one of its original aims, that is, to give musicians the necessary tools to combine finely grained elements from diverse sources in order to create their own editions - which is to say, their own textual instantiations - for the sake of performance. OCVE has long aspired to flexibly conceived, uniquely constructed composite editions of this very kind, hence the discussions at a 2004 project workshop about employing MEI to encode constituent sources so that musicians could extract elements and purposefully combine them if they wished. Several obstacles have prevented such a development, above all the more pressing need to refine the juxtaposition framework at the heart of the variorum. Moreover, MEI was not at an advanced enough stage early in the project to proceed along these lines - and since then there has been insufficient funding to do so. Finally, ethical concerns arise when users are given the capacity to make 'polyglot' scores, an issue that will be explored later.

The fourth and final category under review consists of scholarly initiatives that aspire to DEM status, although some are only partly digital. These 'editions' ostensibly offer more than surrogates of printed material, typically by incorporating multimedia materials. Examples include the Electronic Corpus of Lute Music 


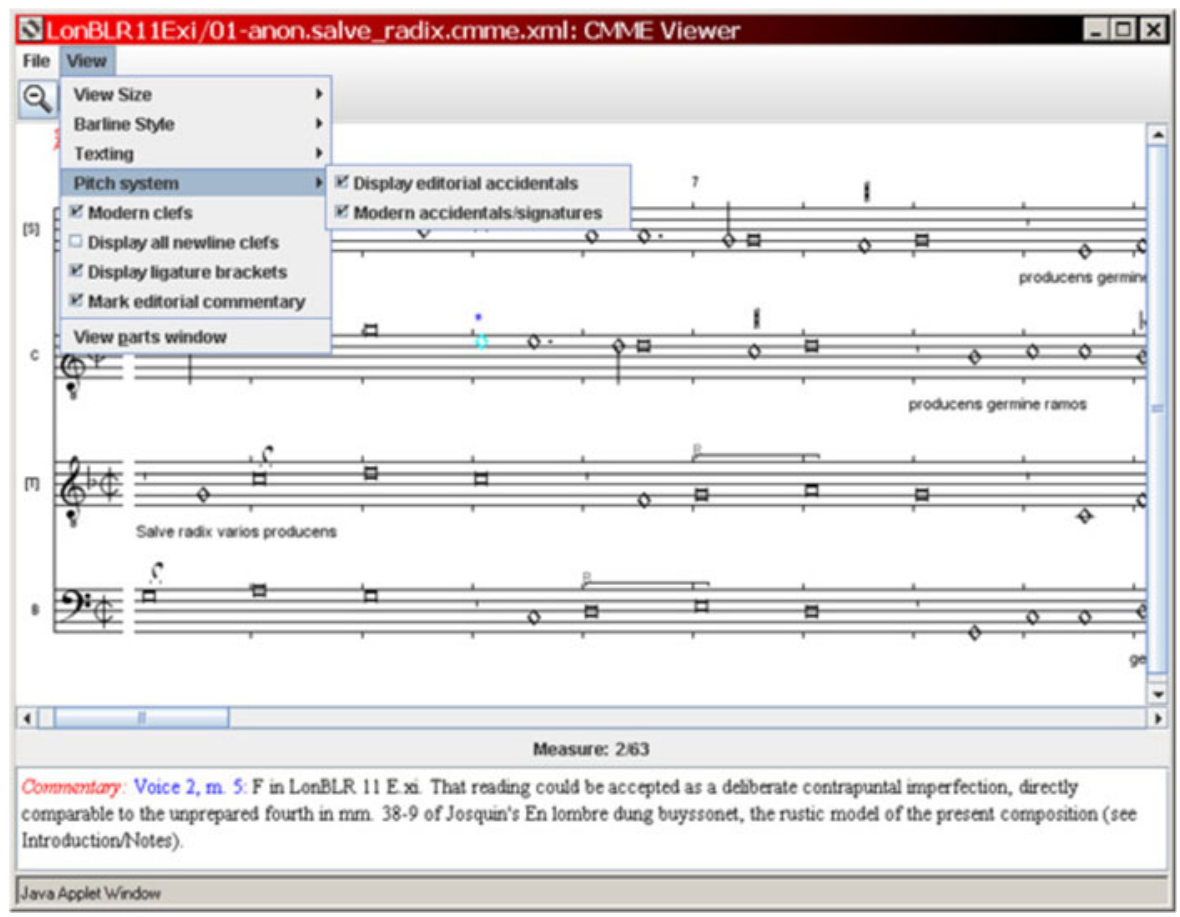

Fig. 4 CMME 'viewer applet', allowing users to choose how they want scores to appear: Anon., Salve radix (www.cmme.org/about\#Screenshots)

(ECOLM), a pioneering project that aimed 'to store and make accessible to scholars, players and others, full-text encodings of sources of music for the Western-European lute (and other relevant sources), together with graphical images from manuscripts and printed music, such codicological and paleographical detail as is helpful to the potential users, and bibliographical data, including, if possible, the texts of important studies' ${ }^{27}$ Other such projects offer hybrid editions, consisting of printed scores suitable for performance or scholarly research, and critical apparatus and supporting materials including facsimiles of manuscripts made available in digital form. One example is the OPERA project (Fig. 6), which uses TEI for digitized librettos and Edirom for digitized critical reports. ${ }^{28}$ The purpose of Edirom here and in other projects is to make 'very complex source situations more transparent ${ }^{29}$ by enabling juxtaposition of images of manuscripts and other materials rather than providing only verbal descriptions thereof. OPERA's output to date is marketed by Bärenreiter, ${ }^{30}$ while similar hybrid editions

27 www.ecolm.org. Another project of interest is the Marenzio Online Digital Edition (www.marenzio.org), but this seems to have stalled: the current website is described as a 'placeholder' to be 'fully updated around July 2016'.

28 See www.opera.adwmainz.de for details of OPERA; https://www.tei-c.org regarding the Text Encoding Initiative (TEI); and www.edirom.de about Edirom.

29 www.opera.adwmainz.de/praesentationsform.html; my translation.

30 For example, Thomas Betzwieser's edition of a 'divertimento teatrale' by Salieri is currently sold at $€ 407$, comprising a hardbound printed score and an 'enclosed credit-card style 


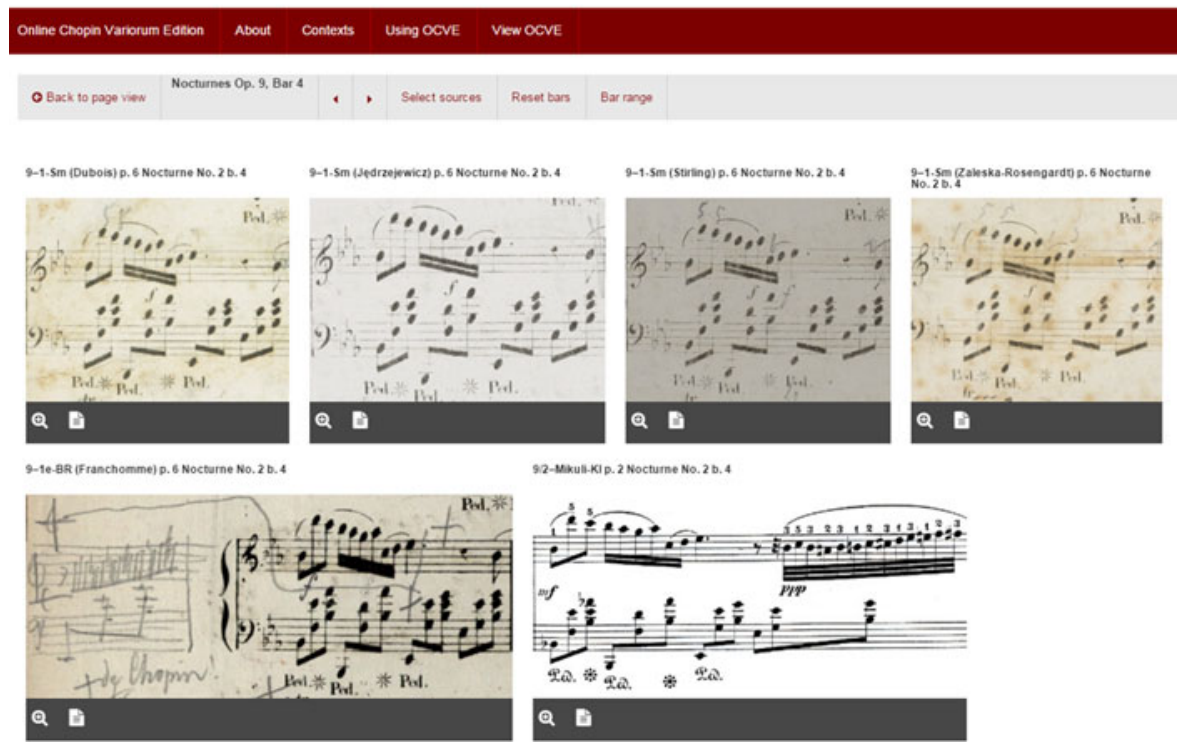

Fig. 5 Online Chopin Variorum Edition - select witnesses of Chopin, Nocturne Op. 9 No. 2 (www.chopinonline.ac.uk/ocve/browse/barview?workid=6394\&page imageid $=77134 \&$ barid $=4$ )

of diverse repertoire ranging from J.S. Bach to Reger are published by Carus-Verlag, which likewise uses Edirom for 'digital archives' reproducing 'all the available sources - manuscripts, first printed editions, as well as other relevant materials such as proofs and letters'. ${ }^{31}$ Carus claims that the digitized critical reports, 'somewhat laborious to read in conventional editions', become 'a pleasure to read: the creation of the works can be reconstructed directly from the sources, and all editorial decisions are transparent and checkable. An extensive encyclopaedic section contains interesting facts about the historical context of the works. ${ }^{32}$

Additional initiatives of this type include Freischütz Digital, which features 'dynamic score rendering' and describes itself as a 'paradigmatic implementation of a genuinely digital edition concept ${ }^{\prime} ;{ }^{33}$ Beethovens Werkstatt, another

USB flash drive' with 'the sources, the text and music editions as well as the critical reports (Edirom)'. See www.baerenreiter.com/en/shop/product/details/BA8811. The OPERA workplan includes editions of nineteenth- as well as twentieth-century repertoire (see www.opera.adwmainz.de/werkauswahl.html), although the extant publications favour earlier music.

31 www.carus-verlag.com/en/digital-media/digital-editions.

32 www.carus-verlag.com/en/digital-media/digital-editions. For example, a full score of J.S. Bach's Mass in B minor accompanied by a DVD with the critical apparatus is currently sold at $€ 199$.

33 https://freischuetz-digital.de; see also https://freischuetz-digital.de/en/demodynamic-score-rendering.html. As the title of the project suggests, its scope is limited to Weber's opera Der Freischütz. 


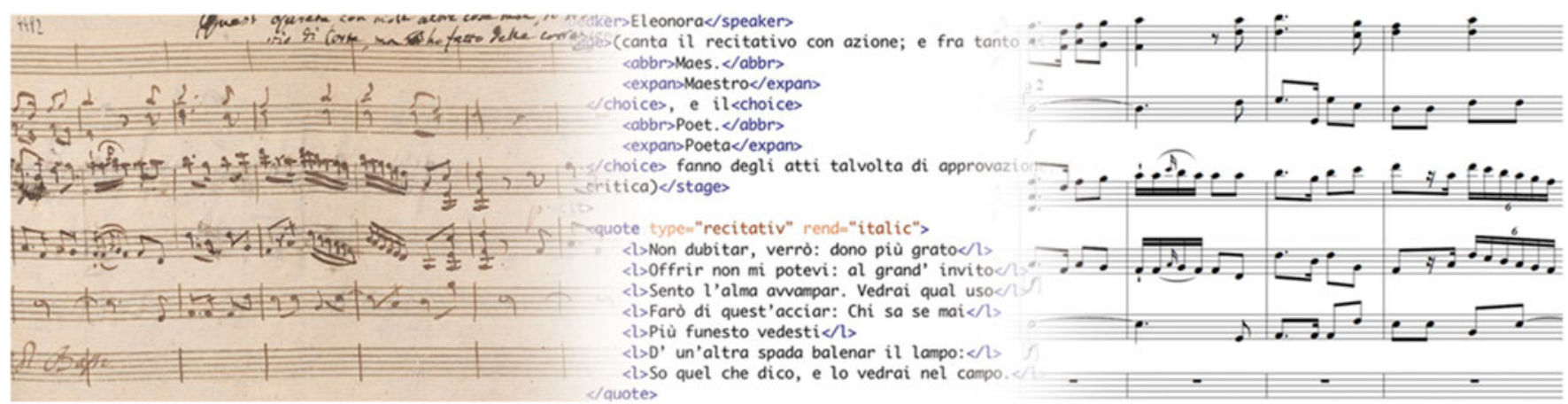

Fig. 6 Montage based on Antonio Salieri, Prima la musica e poi le parole. Left: Autograph (Österreichische Nationalbibliothek, Vienna, Mus. Hs. 4492). Middle: Text edition as XML document. Right: Score published by Bärenreiter-Verlag, Kassel (as of January 2010) (www.opera.adwmainz.de/es/beschreibung.html) 
enterprising, long-term project combining 'two research approaches - Genetic Text Criticism and Digital Music Edition - to investigate compositional process in Beethoven's oeuvre'; ${ }^{34}$ and the Josquin Research Project, which offers various formats for viewing and downloading, as well as tools for online analysis of single or multiple compositions. ${ }^{35}$ Although all of these resources are impressive, the Digital Mozart Edition is potentially of greater relevance to performers. The latter project recently launched the first instalment of an interactive, 'fully digital', MEI-encoded version of Mozart's complete works based on the Neue Mozart-Ausgabe, using the MEI engraving software Verovio and featuring an open access web interface 'MoVi' (digital Mozart score Viewer) with tools and functions supporting 'a dynamic display of the music adapted to the needs of the user, including the production of individual parts' (Fig. 7). ${ }^{36}$ The available resource is as impressive as it is promising, but it nevertheless remains to be seen what sorts of performance scores will be feasible and how they will appear and operate.

All of the initiatives in the third and fourth categories have variably succeeded in producing the 'relational webs of discourse' and 'genuine knowledge sites' described by Hans Walter Gabler in a landmark article on digital scholarly editions from 2010, ${ }^{37}$ collectively achieving most if not all of the music-specific functionalities previously adumbrated by James Grier in $1996^{38}$ and, in more detail, by Frans Wiering in 2009 when outlining his model of the 'multidimensional edition'. ${ }^{39}$ Writing that a digital critical edition of music might 'ideally consist of ... interconnected components' such as digitized sources 'from any relevant medium' (including score facsimiles and video and audio recordings), source encodings, annotations, and 'links to related works', 40 Wiering observed that 'Such a collection of information can be imagined as a multidimensional space, in which different categories of information each occupy a different axis. For example, in addition to the two dimensions of the score, one can imagine versions, emendations, transcription styles and adaptations to performance as additional dimensions to the edition' - all of which could be understood as 'ways of accessing the edition'. ${ }^{41}$

34 https://beethovens-werkstatt.de; my translation. The website includes a number of 'digital case studies' (digitale Fallstudien) which demonstrate the project's functionality, although only a limited amount of repertoire is currently available for inspection.

35 http://josquin.stanford.edu.

36 https://dme-webdev.mozarteum.at/en/music/edition; https://dme.mozarteum. at/movi/en. At present, the resource is limited to some 20 works (listed by Köchel number in a pulldown menu). See Neal Zaslaw's review of a precursor version of the Digital Mozart Edition in Journal of the American Musicological Society 71/2 (2018): 572-86. See below, especially note 79 , for further details about Verovio.

37 Hans Walter Gabler, 'Theorizing the Digital Scholarly Edition', Literature Compass 7/2 (2010): 43-56; doi 10.1111/j.1741-4113.2009.00675.x.

38 James Grier, The Critical Editing of Music: History, Method, and Practice (Cambridge: Cambridge University Press, 1996).

39 Wiering, 'Digital Critical Editions of Music', especially 29-32, 43-5.

40 Wiering, 'Digital Critical Editions of Music', 31. Broude similarly notes the 'variety of ways' in which 'digital musicological editions ... will be able to make the works they represent available', including content and tools of the types discussed by Grier and Wiering. He also observes that such editions 'will allow specialists in performance practice to see the range of ways a piece was realized when it was first circulated in manuscript or print', in addition to making it possible 'for performers to study several texts of a work they are preparing to perform'. See Broude, 'Musical Works, Musical Texts, and Musical Editions', 14-15.

41 Wiering, 'Digital Critical Editions of Music', 31. 


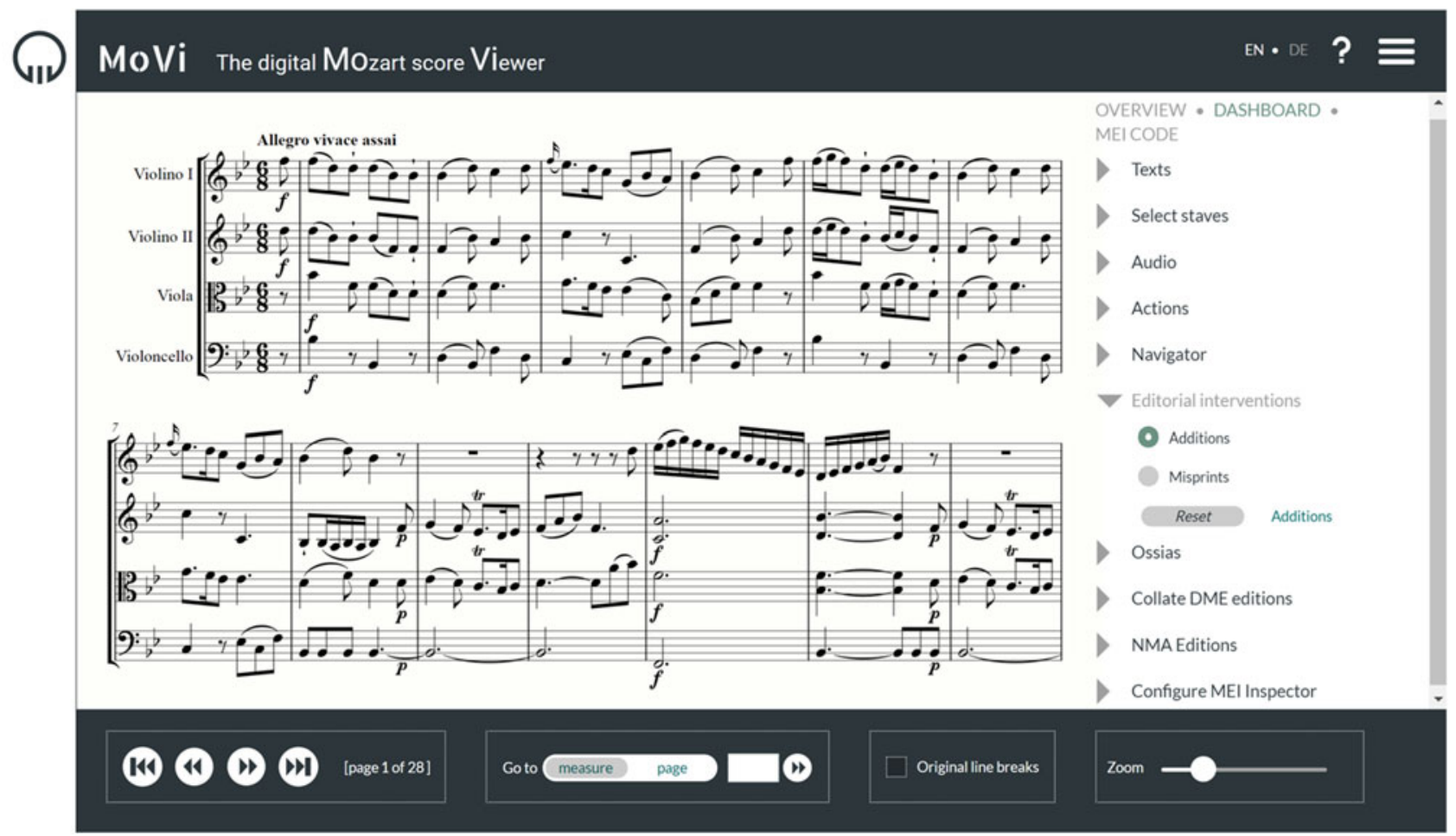

Fig. 7 Digital Mozart Edition - MoVi, the digital Mozart score Viewer: Mozart, String Quartet K. 458, i, bars 1-13 (https://dme.mozarteum.at/ movi/navigator/458/001/01) 
Wiering has recently expressed reservations about the multidimensional model, however, instead of which he now advocates 'a minimalistic concept of digital editing. $^{42}$ This apparent volte-face ${ }^{43}$ has been prompted by concerns about the high cost and extensive effort involved in producing multidimensional DEMs, the 'need for the participation of a [broader] community of academics and citizen scientists', commensurately greater difficulties when sustaining increasingly complex models 'while technology is constantly changing', and 'weaknesses from the perspective of Human Centred Design'. ${ }^{44}$ There is a further issue, which, though not articulated by Wiering, is nevertheless pertinent: that is, existing scholarly DEMs and the multidimensional model in general tend to offer performers not digital editions but digital resources. Apart from the print-based outputs that I have described and, in principle, the Digital Mozart Edition interface, it is not obvious how the resources in either the third or the fourth of my categories would impinge on the music-making of most performers, nor, as in the case of OCVE, does a tangible output for use in performance always emerge. Therefore, even though resources of this kind could be of considerable value to scholar-performers when preparing for performances, they are unlikely - at least in their current form - to offer much to amateur or professional musicians and music teachers who lack an immediate need for detailed critical apparatus or unmediated access to source materials of the types in question. Moreover, there is the risk that without mediation of the sort to which I am alluding, such resources could even have a deleterious effect on the work of musicians 'at large' by overwhelming them with information and/or source material which they are not equipped to fathom.

The survey thus reveals both considerable promise and significant limitations in terms of how current DEMs are or might be used by today's performers. A number of questions follow:

1. What do performers themselves want and expect from DEMs?

2. What is 'enough' in DEMs which supposedly are intended for use in performance? Conversely, what is 'too much'?

3. What, in consequence, should the role of the 'editor' of a DEM intended for performers be, and who is the 'editor' in the first place?

4. More generally, to what extent do existing DEMs realize the potential of digital media, and, especially with regard to performers and performance-related uses, how might they be reimagined to overcome the persistent dependence on print surrogates?

The next part of the essay proposes some answers to each of these questions.

\section{What do performers themselves want and expect from DEMs?}

From this a further question immediately arises: what types of performer is one referring to ${ }^{45}$ Some 40 years ago, Arthur Mendel drew attention to 'a cliché

42 Frans Wiering, 'Minimalism in Digital Music Editing', paper presented at the Online Chopin Variorum Edition workshop on 'Digital Editing and Music', 12 January 2017, St John's College, Cambridge, UK.

43 Note that Wiering identified certain disadvantages of the multidimensional model even in his 2009 article, 'Digital Critical Editions of Music'.

44 Wiering, 'Minimalism in Digital Music Editing'.

45 Note Philip Brett's similar point in 'Text, Context, and the Early Music Editor', in Authenticity and Early Music: A Symposium, ed. Nicholas Kenyon (Oxford: Oxford 
frequently repeated in the policy statements of text-critical editions[,] that they are intended not only for the scholar but also for the practical musician. The scholarly editors of such editions seem to feel called upon to justify them, and to prove that they themselves are in favour of performance. ${ }^{46}$ As I have noted, the same 'cliché' characterizes many DEM projects, which, adapting Mendel's injunction to conventional editors, need to 'keep in mind' that, among the performers who might use them, only 'a few' will be specialists, able to 'arrive at their own understanding of the music no matter how it is presented', whereas others are likely to be 'complete strangers' to that music. ${ }^{47}$ This has obvious implications for both content and mode of presentation, a point to which I return later.

In her article on 'contemplating the e-score', Lisa Hooper claimed that performers and other users want to access digital scores 'on their handheld devices (such as iPads and tablets)'. She also observed that 'musicians, researchers, and performers alike actively engage with the score on a very personal level, meaning [that the ability to annotate and otherwise mark up the score is vital'. Furthermore, 'performers require hands-free page turning capability', while 'professional musicians want one-stop access to a digital score library' ${ }^{48}$ These basic features are found in many of the DEMs reviewed here, especially the commercial products in the second category, and one hopes that future DEMs will not only include but also improve on current performance tools or others like them. What is less common at present, however, is the guidance that some musicians might need or desire on relevant performance practice issues and problems, and on the relationship between those issues and problems and the sources that DEMs reproduce or on which they base their work.

Valuable insights can be gained in this respect from a study by Chiara Bertoglio of how performers use conventional (i.e. printed) 'instructive editions' (IEs), ${ }^{49}$ also referred to by James Grier as 'performing' or 'interpretative editions' and by Ronald Broude as 'enabling editions' ${ }^{50}$ Such editions have tended to attract less musicological attention than their scholarly counterparts (dubbed 'historicizing editions' by Broude), ${ }^{51}$ which, according to Grier, developed after World War Two largely as a reaction to 'the numerous performance instructions added by the editors [of interpretative editions], such as tempo markings, dynamics, phrasing, fingering and pedalling', which 'obscured the original notation ... because very little or no effort at all was expended in differentiating editorial marks from those in the source', in addition to distorting the composer's original intentions more generally. Grier nevertheless acknowledges the enduring need, at least from an historical standpoint, for 'editions that record aspects of the performing style of important performers', which can 'play an extremely important role in the communicating of much great music' and which 'constitute repositories of

University Press, 1988), 98: 'The question might be asked of editors today exactly who is this "performer" for whom they make their editions "practical".'

46 Arthur Mendel, 'The Purposes and Desirable Characteristics of Text-critical Editions', in Modern Musical Scholarship, ed. Edward Olleson (Stocksfield: Oriel Press, 1978): 14.

47 Mendel, 'The Purposes and Desirable Characteristics', 20.

48 Hooper, 'Contemplating E-Scores', 573.

49 Chiara Bertoglio, 'Instructive Editions of Bach's Wohltemperirtes Klavier: An Italian Perspective' (PhD diss., University of Birmingham, 2012).

50 Broude, 'Musical Works, Musical Texts, and Musical Editions', 1.

51 Broude, 'Musical Works, Musical Texts, and Musical Editions', 1. 
information about the performance and interpretation of the work ${ }^{\prime 52}$ - rather like an oral history.

Bertoglio similarly notes the agreement among diverse authors about the importance of IEs as documents of past performance practices' and 'as vehicles and guarantees of traditional and canonically acceptable performances' - that is, as 'witnesses of model performances'. ${ }^{53}$ But she also stresses the significant 'pedagogical function' of IEs, including both 'Performance IEs' (which she likens to a 'written lesson' - these include the celebrated editions of Artur Schnabel and Alfred Cortot) and 'Analytical IEs' (e.g. those of Heinrich Schenker and Hugo Riemann). ${ }^{54}$ In an online questionnaire issued in 2007-08 to Italian pianists, pedagogues and others, Bertoglio asked respondents to state the perceived importance of a range of factors when choosing an edition, and the following criteria (listed here in order of priority) were deemed 'very important':

1. Compliance with the original text

2. Good fingerings

3. Critical apparatus

4. Availability

5. Practicality

6. Explanation of embellishments

7. Tempo and metronome indications

8. Price

9. Pedalling suggestions

10. Presence of preparatory exercises. ${ }^{55}$

Teachers completing Bertoglio's questionnaire claimed to use IEs for 'general advice on interpretation' (73.6\% of respondents), 'indications on performance practice' (71.4\%), 'suggested articulation' (67.9\%), 'suggested fingerings' (59.0\%), 'performance of embellishments' $(59.0 \%)$, suggested metronome indications (58.9\%), dynamics (57.9\%), agogics (56.7\%), pedalling (52.2\%) and expression (51.6\%). They also indicated that the criteria used by their students when selecting a 'first-choice' edition ranged from suggested pedalling (63.3\% of respondents), fingerings $(62.6 \%)$, dynamics $(62.6 \%)$, agogics $(62.2 \%)$ and expression $(62.1 \%)$, to 'performance of embellishments' (57.4\%), metronome indications (56.8\%), 'suggested articulation' (53.2\%), 'indications on performance practice' $(48.4 \%)$ and 'general advice on interpretation' (46.4\%). ${ }^{56}$

Based on these and other findings, Bertoglio offered the following conclusions (with no 'pretension to thoroughness', given the limited size of her survey):

a. 'musical and musicological reasons are normally not the principal ground for choosing an edition';

b. 'scholarly research is not considered a value for which one should pay more';

c. musicians would be willing to pay a 'little more' for 'an edition by a famous performer';

d. 'editorial additions, if recognised as such, are considered as a positive value'; and

52 Grier, The Critical Editing of Music, 10.

53 Bertoglio, 'Instructive Editions', 118, 121, 122.

54 Bertoglio, 'Instructive Editions', 21, 22.

55 Bertoglio, 'Instructive Editions', 94.

56 Bertoglio, 'Instructive Editions', 305. 
e. the publication date of an edition is a criterion for choosing editions 'only because old editions ("authoritative" and "closer to the era of the composer") tend to be privileged". ${ }^{57}$

Although one should not rely too heavily on a single survey of this size, it is striking, though perhaps not surprising, that at least these practitioner respondents regarded editorial additions (including 'general advice on interpretation') as valuable, that they did not prioritize 'scholarly research', and that they sought rather than shunned 'authority' in editions. These attitudes have implications for the sorts of DEM that might be of greatest benefit and relevance to the majority of performers, based on a model analogous to those in the second category above but with potentially significant differences to be discussed later.

\section{What is 'enough' in DEMs which supposedly are intended for use in performance? Conversely, what is 'too much'?}

In an early review of Beethovens Werkstatt, Kristina Muxfeldt observed that '[m]any practicing musicians, musicologists, archivists, and others would surely ... welcome some reflection on why digital editions of Beethoven's works and working materials are needed at all'. She asked: 'is it not enough for musicians to play straight from digitized manuscripts in the manner of the Borromeo String Quartet? ${ }^{58}$

I believe it is by no means 'enough' for musicians to play straight from digitized manuscripts or other 'raw' digital scores, partly because of my experiences with students and other performers who have more or less randomly downloaded readily accessible material from resources like Petrucci without considering or having the knowledge to determine the quality and status of the documents in question. In many such cases, little if any insight can be gained from the resources themselves about specific notational or orthographic problems and about the relative status of the composers' manuscripts, first editions and/or later prints that have been pulled blithely off the internet. This can be extremely problematic: among other things, some performers seem to assume that the music as found in original manuscripts or first editions reflects the composer's intentions in their purest form, without having any awareness of the habitual practices surrounding such documents, the later evolution that might have taken place, and/or the need to conceive of the music as existing in multiple versions. Ironically, some of the most 'dangerous' online material in this respect is nineteenth-century collected editions, which seemingly exude authority (thanks in part to their characteristically stern typography) but which have often been superseded by more informed and less ideologically tendentious counterparts.

Problems of this sort arise in part because 'original performing materials' have now become 'as common as original instruments', a state of affairs once predicted by Philip Brett. ${ }^{59}$ In 2012, Ronald Broude similarly warned that 'being able to

57 Bertoglio, 'Instructive Editions', 112.

58 Kristina Muxfeldt, 'Review: Beethovens Werkstatt', Journal of the American Musicological Society 69/3 (Fall 2016): 858. Muxfeldt is referring to the Borromeo Quartet's use of electronic scores, described in Corinna da Fonseca-Wollheim, 'When Classical Musicians Go Digital', New York Times (9 June 2016); www.nytimes.com/2016/06/12/ arts/music/when-classical-musicians-go-digital.html.

59 Brett, 'Text, Context, and the Early Music Editor', 84. 
manipulate musical texts digitally will tempt people to juggle texts from the past in ways that will be quite unhistorical, foreign to the ways in which the texts were managed when they were originally inscribed ${ }^{60}{ }^{60}$ These risks are not unique to digital musical materials, however: some 60 years ago, Walter Emery, referring specifically to Urtext editions, went so far as to claim that the ordinary practical musician cannot be trusted with an "original text"', which could be 'manifestly wrong': 'there may be a great difference between the notes the composer meant to write and those he meant to be played. In Bach and Handel, as in much earlier and some later music, it is often just as wrong to follow an "original text" literally as it would be to play all Chopin in strict time. ${ }^{, 61}$

Along similar lines, if rather less severely, Bertoglio's study of how performers use 'instructive editions' concluded that '[m]any musicians (students, amateurs, but even teachers and professionals, although in different proportions) have no awareness of the importance of consciously choosing an edition; which criteria to apply; which criteria may have been applied in editing; why and how to make a good choice; [and] what an IE may imply for its user'. ${ }^{62}$ To support her claims, Bertoglio cited the views of Mischa Meller ('many teachers and students ... seem to be virtually unaware of the nature and quality of the editions they use so trustingly' $)^{63}$ and Artur Schnabel ('a multitude of musicians and musical persons ... simply take what is handed to them'). ${ }^{64}$

These conclusions - though by no means universally applicable - suggest that more is needed than 'the music itself' if performers are to make informed decisions about how to render the notation in front of them, whether that notation is on the page or on a screen. One solution that might be adopted in developing a more ambitious but performer-friendly DEM model is to provide standard critical apparatus, whether in separate documents (as in the Web Library of Seventeenth-Century Music) or 'chopped up' on a bar-by-bar basis (as in the Henle Library - see again Fig. 1d). The inevitable risk that such material will be consulted by musicians no more systematically than critical commentaries at the back of printed volumes makes it all the more important to supplement it with both 'open discussion of the possibilities' arising from the notation and 'measured judgement[s] as to which courses of action are preferable', both of which Brett claimed that editors should offer as a matter of course. ${ }^{65}$ This requires the exercise of individual or collective editorial agency, going well beyond the mere provision of essays about the composer's biography, the genres in question and other ostensibly pertinent topics which have limited potential to inform the decisions made by performers in the heat of action. Nor is it 'enough' to make available the sometimes huge amounts of facsimile and other multimedia material assembled in the scholarly digital edition projects previously surveyed. In short, more focused interventions of the types outlined below are needed.

Rather than engaging in overkill or paying only lip service, DEMs intended primarily for performers therefore should guide and judiciously inform their users.

60 Broude, 'Musical Works, Musical Texts, and Musical Editions', 15.

61 Walter Emery, Editions and Musicians (London: Novello, 1957): 39.

62 Bertoglio, 'Instructive Editions', 114.

63 Mischa Meller, 'Some Critical Comments on Modern Editions of the Piano Classics', American Music Teacher 4 (Sep./Oct. 1954): 1.

64 Artur Schnabel, Music and the Line of Most Resistance (Princeton: Princeton University Press, 1942): 86.

65 Brett, 'Text, Context, and the Early Music Editor', 254. 
Such guidance should address not only how constituent or related source material might best be understood, but also the performance practice issues arising either in general or in given passages, whether to do with original or subsequent performance contexts. In other words, what is needed is a new form of 'instructive edition' or 'enabling edition' exploiting the affordances of the digital environment but with practical utility as an overriding design consideration. Two unlikely models for this will be considered later.

3. What, in consequence, should the role of the 'editor' of a DEM intended for performers be, and who is the 'editor' in the first place?

The foregoing discussion prompts additional questions about the role of the 'edi-

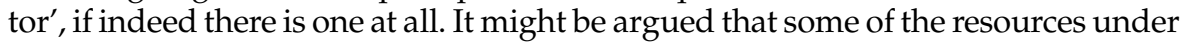
review have the potential to extend editorial agency to individual users - and such democratization is highly desirable, at least in principle. But, again, a simple handover of responsibility is not 'enough', as I have indicated.

The principal issues at stake concern first of all the nature and purpose of 'critical commentary' targeted specifically at performers within individual DEMs, and secondly the performance-related editorial overlay that might also be provided, including 'general advice on interpretation'. In both respects, multidimensionality of the sort once advocated by Frans Wiering, albeit to different ends, is likely to be propitious. Depending on the context, explanatory material in audio, video and/or textual formats could be of benefit, focusing on aspects of the source material in the DEM with direct implications for performance, and on the particular performance approaches that might be taken to them. That material might be modelled in part on supplementary information of the type on offer in the Peters Masterworks series, though, as previously noted, it would ideally go beyond general background texts about the composer's biography, the musical genres in use, and so forth - information with limited potential to influence musicians' decision-making during performance itself. As for practice contexts, the 'chopped-up', bar-by-bar presentation currently used for Henle Library score comments would be especially apposite for performance-orientated textual explanations of this kind. Another possibility would be to construct on-screen walk-throughs of select material, whereby individual notational features or other distinctive elements of a manuscript or printed source are explained and discussed in sequence. In principle, the completion of one or more walk-throughs along these lines might even be made a prerequisite before an individual user could proceed to the full body of material in a given DEM.

Irrespective of the mechanisms employed to transmit the material, both mediated source information and commentary on performance practice issues could fruitfully be given by those producing digital 'enabling editions', for the reasons that I have already articulated. Their editorial input in this respect would extend beyond that of mere curator, thereby solving a problem identified roughly a decade ago by James Stephen Murphy, who claimed with regard to editions of literary works that (in Christina Georgiou's words) 'some digital projects have "killed the editor"', in that 'more emphasis has been placed on the abundance of information presented, rather than on the provision of a usable reading text'. ${ }^{66}$ Murphy

66 Christina Georgiou, 'The Historical Editing of Mozart's Keyboard Sonatas: History, Context and Practice' (PhD diss., City University London, 2011): 356. 
complained that 'if the only online options are electronic archives and transcriptions of outdated, flawed editions, we run the risk of losing something valuable as well: not just the editor, who has been turned into an archivist, but also an understanding of texts as objects of interpretation and argument, or the products of interpretation and argument'. ${ }^{67}$

Relevant philological and performance-related information might be generated in collaborations between performers and one or more DEM 'editors', thereby recapturing the insights found in many an 'IE' from the past. An enterprise of this sort in the context of a modern printed edition can be found in the Beethoven Piano Sonatas series launched some 15 years ago by Henle Verlag, which is co-edited by musicologist Norbert Gertsch and concert pianist Murray Perahia. ${ }^{68}$ Apart from the fingering added by Perahia, however, there is no apparent editorial overlay for performers in these Urtexts, especially when compared with the Bärenreiter Brahms and Peters Chopin volumes described below. It should be noted that, if presented in a digital format, editorial overlay of the kind that performers themselves often find valuable could be turned off and on as required, rather like the suggested fingerings in the Henle Library. Indeed, there is scope for a vast range of toggle-able editorial interventions in future digital 'enabling editions', yielding a healthy distinction between potential practice and performance uses of those DEMs, as I discuss later.

In addition, a given DEM portal might either form part of or give access to a network of digitized 'instructive editions' and other source materials of possible benefit to individual performers seeking practical information and/or 'general advice on interpretation'. Such access might be effected through links either to editions which are already in digital form, e.g. on Petrucci, or to conventional scores which the DEM 'editor' digitizes and then assembles in a modular network of material providing the opportunity for synergistic comparison of diverse sources and for construction of a uniquely tailored 'relational web of discourse', but without necessarily succumbing to the monolithic aims of some multidimensional DEMs.

Ideally, however, there should be a degree of interoperability among the sources in such a network so that individual musicians could extract elements from one or more digitally encoded scores and then paste them into a 'master' DEM that they tailor for use on single or multiple performance occasions. As I have noted, intermixing of this type has been a long-term aspiration of OCVE, and it is what Ronald Broude had in mind when he observed that DEMs

will make it possible for performers to study several texts of a work they are preparing to perform. And because such editions will enable users quickly and conveniently to identify differences among texts of the same work, they will empower users to become their own editors: each user will be able to establish his own text by selecting elements from the various sources and combining them to create a new text; it will be possible, for example, to select the basic lines of a keyboard piece from one source and the ornamentation from another. ${ }^{69}$

\footnotetext{
67 James Stephen Murphy, 'The Death of the Editor', Essays in Criticism 58/4 (Oct. 2008): 303.

68 William Drabkin reviews several early volumes in the series in Nineteenth-Century Music Review 3/1 (2006): 156-8.

${ }^{69}$ Broude, 'Musical Works, Musical Texts, and Musical Editions', 15.
} 
Broude added that such a procedure is 'followed today by many a performer preparing a piece for a recital, but digital editions will make it ever so much easier than it is now'. Grier too commented that ' $[w]$ hen performers/editors take it upon themselves to supplement the performing indications provided by the composer, they do no more than express in writing the freedom most composers expect them to assume in performance' ${ }^{70}$

With on/off toggling, pop-ups, and other modes of viewing or not viewing information, digital platforms offer solutions to one problem identified by Grier in connection with the 'instructive editions' of Beethoven's Piano Sonatas by Artur Schnabel ${ }^{71}$ and of Chopin by Alfred Cortot. ${ }^{72}$ Although both are renowned for their copious practical notes for performers, the downside, according to Grier, is that '[i]n places, the prolixity of the commentary swells up to drive all but a system or two of music from the page'. Therefore, in their original printed form, the 'chief utility ... of the editions by Schnabel and Cortot is for study, as opposed to practising, at the keyboard. They are not really practical for playing, even though they contain a great deal of useful information for the performer'. ${ }^{73}$ In digital form, by way of contrast, commentary text of this kind could simply be turned off during performances, which once again confirms that, potentially, a DEM offers many more modalities in terms of practical use than a printed edition.

As for the nature of the guidance that performers receive from those directly responsible for creating a DEM, from other performers working in collaboration with DEM teams, or by consulting a network of 'IEs' and other sources, it is useful to heed Arthur Mendel's suggestion that '[i]f editors really want to help the performer, what they should do is not provide him with ready-made answers to questions that have no definitive answers, but encourage him in every way possible ... to think out answers for himself' ${ }^{74}$ According to Mendel, 'performers do not need spoon-feeding by editors', not least because practical musicians are 'not as often unwilling to do some thinking of [their] own as editors frequently imagine'; he also warns of 'the danger of imposing the editor's choices on performers'. ${ }^{95} \mathrm{~A}$ further point is raised by Paulo de Assis in connection with instructive editions of the type under consideration: 'Given the fact that increasingly more performers have a solid academic training (enabling them to become artist-researchers, who understand how to critically tackle different kinds of sources), such interpretative editions could very well regain a certain importance - particularly among young students and performative colleagues'. ${ }^{76}$ This is a far more positive assessment of performers' knowledge about and ability to use editions than those of Emery, Schnabel, Meller and the others quoted above. For all these reasons, exemplars

70 Grier, The Critical Editing of Music, 153.

71 Beethoven, 32 Sonatas for the Pianoforte, ed. Artur Schnabel, 2 vols (New York: Simon and Schuster, 1935).

72 Alfred Cortot, Éditions de Travail des CEuvres de Chopin (Paris: Éditions Salabert, 194147).

73 Grier, The Critical Editing of Music, 154, 155.

74 Mendel, 'The Purposes and Desirable Characteristics', 23. Recall the comments of Brett, quoted above, about the performer's need for 'open discussion' and 'measured judgement' ${ }^{\prime}$ on the part of the editor.

75 Mendel, 'The Purposes and Desirable Characteristics', 14, 17, 20.

76 Paulo de Assis, 'Beyond Urtext: A Dynamic Conception of Musical Editing', in Paulo de Assis, Mieko Kanno and Juan Parra Cancino, Dynamics of Constraints: Essays on Notation, Editing and Performance (Leuven: University of Leuven Press, 2009): 13. 
provided by an editorial team could be of greater value to musicians than fully developed editions aiming to be exhaustive in every particular.

It therefore seems appropriate to encourage the development and implementation of a DEM model that promotes the sharing of knowledge, authority and agency. Such a model would be based on an understanding of editions as sites of creative collaboration and interaction, dynamically exercised in line with the prerogatives of individual participants and the exigencies of given contexts.

4. More generally, to what extent do existing DEMs realize the potential of digital media, and, especially with regard to performers and performance-related uses, how might they be reimagined to overcome the persistent dependence on print surrogates?

Hooper's avowal (quoted above) that the digital materials in her exercise were 'ultimately printed for use' is telling because it points to performers' apparent preference for printed scores, and possibly also to their unfamiliarity or relative lack of ease with digital counterparts. Her conclusion also has clear implications for how the digital materials in question might be reimagined and re-presented. In this regard, note Hans Walter Gabler's claim that, as of 2010, digital editions of texts tended to be conceived 'in terms of print' and basically were 'spill-overs from the print medium': while generally providing 'an increase in comfort', such editions 'betrayed little ground-breaking re-conception'. This was because stasis - 'ineluctably a feature of the material medium' - had not 'ceded to the dynamics inherent in the digital medium'. ${ }^{77}$

The survey here indicates that, to a surprising extent, Gabler's observations apply to current digital editions of music in so far as performers are concerned. Of those reviewed thus far, only one - Gustaf - decisively transcended the restrictions of a print model by giving musicians a digital platform on which to generate and engage with tailormade performing materials in the interactive manner that I am advocating. ${ }^{78}$ Be that as it may, even the most breathtaking new DEM design will have only limited success if performers are not motivated to use it, and for that to be achieved a shifting of preferences and practices away from print is an essential prerequisite. The snag is that a text of some sort - however provisional - is required for performance purposes, and this means that the capacity to achieve both flexibility and fixity must be built into future digital editions of music.

A tasklist for those designing DEMs specifically intended for performers might therefore run as follows:

1. Give musicians a 'base text' in digital form - ideally a score which has claims to be reliable and authoritative (however defined), as opposed to 'any old' edition.

2. Using multimedia, pop-ups, toggles and/or other techniques (all of which are technically straightforward, as evidenced by existing digital resources), offer relevant information about the source(s) used to prepare the base text as well as others directly related to it, along with commentary on the performance practice issues that the music raises both in general and on a more detailed (e.g. bar-by-bar) basis.

77 Gabler, 'Theorizing the Digital Scholarly Edition', 48.

78 It is not yet clear whether the Digital Mozart Edition's MEI-encoded platform will have similar interactive potential. 
3. Offer additional 'training opportunities' such as walk-through demonstrations of select passages and/or entire pieces.

4. Provide a suite of performer-friendly tools for annotation, automatic pageturning, location identification, on/off toggling of fingerings and other markings, and so forth (possibly drawing on existing models such as Henle and Tido).

5. Give users the functionality they would require to alter any element in the base text (as in the Gustaf app), as opposed to just annotating it.

6. As part of that functionality, provide a means of importing elements into the base text from other digitized scores, possibly within a network of material linked to the given DEM.

7. Ensure that individual performers could trace the provenance of all changes that they make to the base text, while also allowing them to save and then retrieve any number of discretely tailored versions of that text.

8. Also ensure that at any stage in engaging with a work a more or less clean and attractive 'performance text' could easily be fashioned from the tailored base text, for display on a tablet or other device to be used in live music-making.

This tasklist - which is by no means exhaustive - covers the most essential points to emerge from the discussion so far. As indicated, it would be straightforward to undertake tasks 1 to 5 , given that the necessary technology has been tried and tested in numerous precursor projects, many using open source code or processes. Although tasks 6 and 7 have fewer precedents and therefore pose greater challenges, the latter could be overcome, by way of example, through the use of the VerovioHumdrumViewer (VHV) ${ }^{79}$ and, in particular, by building on the work of an ambitious EU-funded project currently being pursued by the Fryderyk Chopin Institute in Warsaw. ${ }^{80}$ In that project, MusicXML files of the works of diverse Polish composers are first converted to Humdrum using the VHV; the Humdrum encoding is then corrected and enriched as appropriate, before being converted to MEI and rendered dynamically with Verovio. ${ }^{81}$ The eventual internet resource will include functionality of the very type outlined under tasks 5,6 and 7, allowing individual users to import musical elements from a range of sources or to remove unwanted details from a base text for the purposes of either study or performance, with traceable provenancing to avoid confusion and to minimize the risks of indiscriminate intermixing. Thanks to these features, users will be

$79 \mathrm{VHV}$ 'is an online digital music editor and interactive notation rendering interface for Humdrum files, located at http://verovio.humdrum.org'. The 'three major software components used to create the VHV website' are: 1) Verovio (defined as 'music notation rendering in $\mathrm{C}++$ using MEI, with data imports from Humdrum and MusicXML and exports into SVG and MIDI'; see also www.verovio.org); 2) Humlib ('musical data conversion and analysis tools in $\mathrm{C}++$, using Humdrum, with imports from MusicXML and MEI and exports into MEI and MIDI'; see also https://humlib.humdrum.org); and 3) Ace (an 'embeddable code editor written in JavaScript'; see https://ace.c9.io). For further discussion of VHV see https://doc.verovio.humdrum.org.

80 See the press release at www.ctvnews.ca/entertainment/poland-to-release-chopincollection-online-by-2020-1.3782891, which states that visitors to the project website (due for release in 2020) 'will not only be able to search for and download particular scores or excerpts but will also be able to run all kinds of analyses of the rhythm, harmony, melody and other aspects of the music'.

81 For a more technical description of the process see https://doc.verovio.humdrum. org/index.html. I am grateful to Laurent Pugin for his advice on this passage. 
able to create multiple discrete versions as envisaged by Broude and as advocated here. As for task 8 , whether this can be realized will depend on the availability of on-the-fly rendering of the highest quality, as already achieved by LilyPond ${ }^{82}$ and as sought by Verovio among other projects.

A few additional observations are warranted. First, as I have indicated, the paramount considerations in designing such a DEM should be practicality and performability, and in this respect adherence to the 'minimalistic' principles recently articulated by Frans Wiering could be advisable. Secondly, as previously noted, it would be beneficial if the editor and/or designer provided users with exemplars of worked-up editions and relevant commentary to demonstrate how a base text could be inflected on the basis of designated criteria and with certain types of use in mind. Thirdly, a social dimension of the kind advocated by Peter Robinson and others might usefully be incorporated, ${ }^{83}$ so that individual decisions about given musical texts are taken not in isolation but in dialogue with a 'community of practice'. Finally, in principle, the ability to combine elements from diverse sources as stipulated under task 6 above could be policed by the editor and/or designer, i.e. by preventing instances of 'borrowing' and intermixing that would give birth to a musical Frankenstein - although placing restrictions on the user would raise thorny ethical issues.

During the most recent phase of the OCVE project, Laurent Pugin was commissioned to produce a working prototype of a digital edition in which given bars in the posthumously published Waltz in F minor by Fryderyk Chopin could be substituted by counterpart passages drawn from a handful of manuscript sources produced at different times by Chopin. ${ }^{84}$ This proof-of-concept was based on multiple Urtexts of the sources in question as found in The Complete Chopin: A New Critical Edition, ${ }^{85}$ directly addressing tasks $1,6,7$ and 8 above and with the potential to satisfy tasks $2-5$ as well. With only a minimal amount of further development, it would have been possible to devise a DEM platform allowing an individual pianist to produce one or more notated texts reflecting the 'improvisatory' invention for which Chopin was renowned and that I for one seek in my own performances

82 LilyPond is a 'powerful music engraving software that results in beautifully engraved music. All of LilyPond's style settings, font designs and algorithms have been inspired by the finest hand-engraved music. LilyPond output has the same strong, balanced and elegant look as the best-engraved classical scores.' For further details see http://lilypond.org.

83 See e.g. Peter Robinson, 'Towards a Theory of Digital Editions', Variants 10 (2013): 105-31.

84 The prototype was prepared on the basis of structured MEI rendered by means of Verovio. Compare the technologically antediluvian resource mUltimate Chopin (http:// multimatechopin.com), which enables users to intermix variant material in the form of preprepared snippets of images which in effect are plugged into a given 'main text', as opposed to being generated on the fly on the basis of encoded representations of the music.

85 See Waltzes, ed. Christophe Grabowski, in The Complete Chopin: A New Critical Edition (London: Peters Edition, 2006). This volume contains three versions of the F minor Waltz, respectively based on a manuscript presented by Chopin to Marie de Krudner in June 1842; another based on a different autograph manuscript owned by the Rothschild family, but with variants printed alongside the main text taken from three additional manuscripts; and the third based on the Polish first edition from 1852, published three years after Chopin's death and prepared from a manuscript notated by Chopin for the album (now lost) of Countess Plater. For discussion, see John Rink, 'Chopin and Improvisation', in Chopin and His Musical World, ed. Jonathan D. Bellman and Halina Goldberg (Princeton: Princeton University Press, 2017): 265-7. 
of the F minor Waltz, as described in a recent essay. ${ }^{86}$ What is needed first and foremost, then, is not more advanced technology but rather an appropriate conception and design as well as the wherewithal to implement it. ${ }^{87}$

Given the imperative to wean performers off print if digital editions are to take root in musical practice, it might seem perverse to cite two print-based editions as possible sources of inspiration, or at least points of reference, for the more ambitious DEM concept that I am encouraging. The fact that both are of compositions from the nineteenth century is salutary, given the relative lack of attention to music of this period in DEM projects to date ${ }^{88}$ owing to the notational complexities and concomitant technical challenges associated with such repertoire, likewise the especially thorny philological as well as interpretative problems that arise in works from c. 1800 onward. One of the print-based exemplars considered here is The Complete Chopin series, in which six volumes have been published by Peters Edition, ${ }^{89}$ while the other is the Brahms Sonata for Cello and Piano in E minor Op. 38 published by Bärenreiter in 2015 along with a companion booklet on performance practices in Brahms' chamber works. ${ }^{90}$ The Complete Chopin volumes are based on a 'best-text' approach, thus preserving a notional fidelity to one designated source but with important variants published either alongside the main music text, in footnotes or in the Critical Commentary, or - in the case of smaller-scale details - incorporated into the music text in a typographically distinct form. ${ }^{91}$ In essence, this is a variorum print edition which has a full critical apparatus but is intended primarily for performers, as is evident from the content of the introductory essays in all volumes on 'genre and genesis', 'form and design',

86 Rink, 'Chopin and Improvisation', gives examples of both an underlying plan for and select passages in hypothetical 'improvisations' compiled by the author from the disparate sources reproduced in Waltzes, ed. Grabowski.

87 The issue of funding future DEMs is anything but trivial; Raffaele Viglianti for one has suggested that 'dialogue', which is to say collaboration, with commercial publishers might be necessary for the development and sustainability of digital editions of music; Raffaele Viglianti, 'Editing Music for the Digital Medium: Theory and Practice Through a Case Study on Carl Maria von Weber's Romantic Opera Der Freischütz' (PhD diss., King's College London, 2014): 207. It is beyond the scope of this article to address the full gamut of issues to do with financing, sustainability and so forth of relevance to the further evolution of DEMs.

88 Note the significant proportion devoted to repertoire from before 1800 in the third and fourth categories of DEMs surveyed above.

89 Preludes, ed. Jean-Jacques Eigeldinger (2004); Ballades, ed. Jim Samson (2006); Waltzes, ed. Grabowski; Concerto Op. 11 and Concerto Op. 21, ed. John Rink (respectively 2008 and 2010); and Impromptus, ed. John Irving and Christophe Grabowski (2011), all published by Peters Edition in London. The first two volumes were reviewed by Jonathan D. Bellman in Notes 65/4 (June 2009): 857-60.

90 The edition (Brahms, Sonata for Violoncello and Piano in E minor Op. 38, ed. Clive Brown, Neal Peres Da Costa and Kate Bennett Wadsworth (Kassel: Bärenreiter, 2015)) is available as BA 9429, and the companion volume (Clive Brown, Neal Peres Da Costa and Kate Bennett Wadsworth, Performance Practices in Johannes Brahms' Chamber Music (Kassel: Bärenreiter, 2015)) as BA 9600. See Michael Musgrave's review of the latter in Performance Practice Review 21/1 (2016); doi 10.5642/perfpr.201621.01.01; http://scholarship.claremont.edu/ ppr/vol21/iss $1 / 1$.

91 For example, dynamic indications, pedallings, articulation marks and slurs based on Chopin's annotations in the scores of his students appear within round brackets in the main text, whereas fingerings from student scores are printed in italics, as against the roman type used for fingerings from the principal source. 


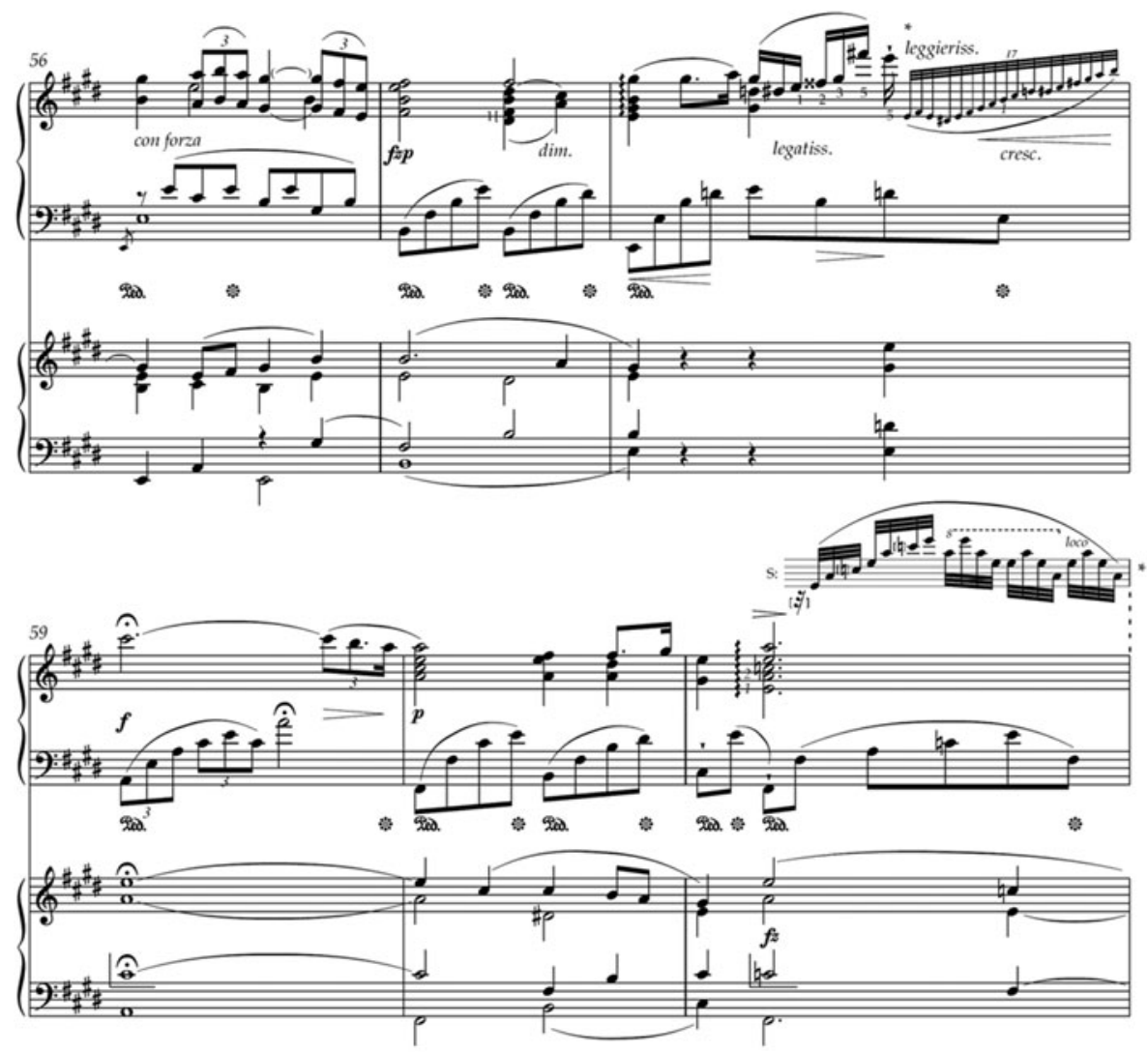

* See Critical Commentary.

Fig. 8 Bars 56-61 in second movement of Fryderyk Chopin, Piano Concerto No. 1 in E minor Op. 11, ed. John Rink (Edition Peters No. 7529) [The Complete Chopin: A New Critical Edition], (C) 2010 by Peters Edition Ltd, London. Reproduced by permission.

and performance practice issues. Further performance-related information is given in the 'Notes on Editorial Method and Practice' and passim in the Critical Commentary on a bar-by-bar basis. ${ }^{92}$ As for the possibility of introducing variants into one's performances, consider the interesting but problematic excerpt from the second movement of the Concerto Op. 11 reproduced in Figure 8. Here a variant from the score of Chopin's student Jane Stirling is given in bar 61, along with an asterisk directing musicians to the Critical Commentary (see the footnote on the

92 For example, the 'Notes on Editorial Method and Practice' (which appear in all volumes in the series) include the following: 'Right-and left-hand parts may be divided between the two staves when such a disposition is vital to the original sense or better conforms to hand positions. This is how Chopin tended to notate his music, and it may be significant with regard to articulation and sonority.' As for the Critical Commentary, performance advice is given about such features as Chopin's notation in Op. 11, second movement, bars 255 and 257, in particular about the oblique line ('liaison') pencilled into the score used by Chopin's pupil Camille Dubois. 
page). Another asterisk appears above the rapid figuration in bar 58, again referring users to the Critical Commentary. The latter provides additional variants from the score used by another student, Caroline Hartmann, for bars 58 and 59, and in the comment about bar 59 there is mention of a similar variant in that bar in the score of Camille Dubois (not shown in the edition). The rationale behind not including the Hartmann and Dubois variants in the main body of the edition is simply that their provenance cannot be readily traced to Chopin, whereas the variant from the Stirling score has somewhat greater authority, even though it too was not notated by Chopin (nor, it seems, by Stirling herself). Moreover, in the original source it was inscribed in the margin to the left of bar 59, not bar 61, hence the decision of some editors to regard it as an ornamental variant intended for bar 59. In the Polish National Edition, for example, no fewer than three ossia indications are given for each of bars 58 and 59, in addition to another variant presented as a footnote to bar 61 and a further one within bar 61, alongside extensive discussion in the Critical Commentary as well as further discussion in the separate Performance Commentary. ${ }^{93}$ Both the Polish National Edition and The Complete Chopin deserve credit for offering performers a host of possibilities to vary select passages in the manner of Chopin; but both suffer from the constraints, which is to say the inimical fixity, of the printed page, as a result of which keen performers using either score would be forced to flip back and forth between the main text and the commentary material, all the while mentally juggling diverse musical options as they decide which to use on a given occasion.

All of this highlights the potential of the digital environment to capture the dynamic flux that is the lifeblood of music. If these editions or others like them were reconceived as DEMs along the lines recommended above, the manifold options could appear in a menu with accompanying explanations in pop-ups or another suitable form such that performers could choose among them in a hasslefree manner, with the capacity to generate as many singular performance texts as they wished. In this respect the musicians would come even closer to the practice of Chopin himself, who continually tinkered with his works not out of dissatisfaction with earlier attempts but because his fervid imagination inspired him to hear the music anew on every encounter that he had with it. Thus, a digital edition of Chopin has the scope to overcome the rigidity of the nineteenth-century 'work concept' $^{\prime}$ and to foster the experiencing of music as a continually evolving creative process.

A complementary lesson can be learned from the Bärenreiter edition of Brahms' E minor Cello Sonata cited earlier, which, although not a variorum, nevertheless invites 'dynamic' comparison of and interaction between alternative versions of the cello part. Like The Complete Chopin, this edition aims to be musicologically rigorous and authoritative but is intended primarily for performers. Among other things, it features a Preface in English and German giving background information to the composition, publication and early performances of the piece; a 'Performing

93 Chopin, Koncert e-moll, Wersja na jeden fortepian, ed. Jan Ekier and Paweł Kamiński (Warsaw: FWN, 2001). The Polish National Edition, which is also a print variorum, is based on editorial principles different from those underlying The Complete Chopin, as it aspires to an idealized (i.e. composite) version of the music rather than a 'best-text' reading of the source deemed closest to Chopin. Both editions, incidentally, are 'policed' in the manner described above, in that only some of the variants attributable to Chopin are reproduced - partly because of the constraints of the printed page - and thus are available for use in 'improvisatory' performances. 
Practice Commentary', also in English and German, which first addresses general matters before turning to rhythm and timing, dynamics and accentuation, etc., followed by 'bar-by-bar' (in fact, selective) commentary; and a Critical Report in English only. The separate Performing Practices volume to which I have referred supplements the information in the edition proper. The feature of greatest relevance to our discussion is the inclusion of two versions of the cello part, in addition to an Urtext of the combined piano and cello parts (see excerpt in Fig. 9a). The separate cello parts respectively comprise an Urtext on the one hand and what amounts to a performing edition on the other (Fig. 9b), the latter of which includes fingerings and bowings and 'seeks to recover some of the messages and performing practices that Brahms expected his notation to convey to a performer' ${ }^{94}$ To prepare this 'marked-up' version, reference was made to 'three early performing editions, including two by performers who had a direct musical connection to Brahms', as well as a range of performance-related research. ${ }^{95}$

This 'enabling' edition exemplifies, or at least hints at, some of the key features of a DEM prepared on the basis of the tasklist above. Not only does it offer an abundance of practical information for performers which, if 'chopped up', could be attached to individual bars or otherwise presented in a more digestible form than is possible in print, but it also features an inspired combination of 'base text' (i.e. the Urtext of the cello part) and tailored 'performance edition' (the counterpart with fingerings and bowings), the latter of which conceivably could have been prepared by an individual musician using a digital platform to consult and then import elements from other IEs, and so forth. The difference, of course, is that here we have only two (notionally fixed) versions, whereas in a digital context an infinite number could emerge. Note for instance the multiple bowings in bar 3 (Fig. 9b), which are taken from different sources. ${ }^{96}$ Ironically, despite the flexible performance approach that is invited, the somewhat confusing appearance on the printed page makes it harder to read between the lines. In other words, the fixity of print undermines the flexibility that a digital platform would inspire and enculture.

It is unlikely that digital editions of music will ever fully replace printed editions but that should not be our goal anyway. The fact is that print has certain advantages over digital, just as digital has certain advantages over print. ${ }^{97} \mathrm{I}$ have argued that in developing future DEMs for performers, the aim instead should be to

94 Brahms, Sonata Op. 38, ed. Brown et al., VI. The Urtext cello part was edited by Brown, while Bennett Wadsworth is credited with the fingering and bowing in the 'marked-up' cello part.

95 Brahms, Sonata Op. 38, ed. Brown et al., VI.

96 Herewith the commentary on this bar: 'Vc: The shorter of the two slurs is present in the autograph, but the longer one with the portato articulation comes from the first edition (see Critical Report). This longer slur, which [Cornelius] van Vliet retains [in his 1921 performing edition], may indicate a bow technique that uses longer bow strokes for the entire melody. [In his 1926 performing edition, Julius] Klengel removes the slur and adds tenuto marks to the two separate 8th-notes, slurring the dotted figure at the end of the bar. The alternate bowing shown is Becker's'; Brahms, Sonata Op. 38, ed. Brown et al., IX.

97 Compare the conclusion reached by a recent project on the 'academic book of the future': 'It seems that the future is likely to be a mixed economy of print, e-versions of print, and networked enhanced monographs of greater or lesser complexity'; Marilyn Deegan, Academic Book of the Future Project Report: A Report to the AHRC and the British 


\section{Sonate}

Opus 38
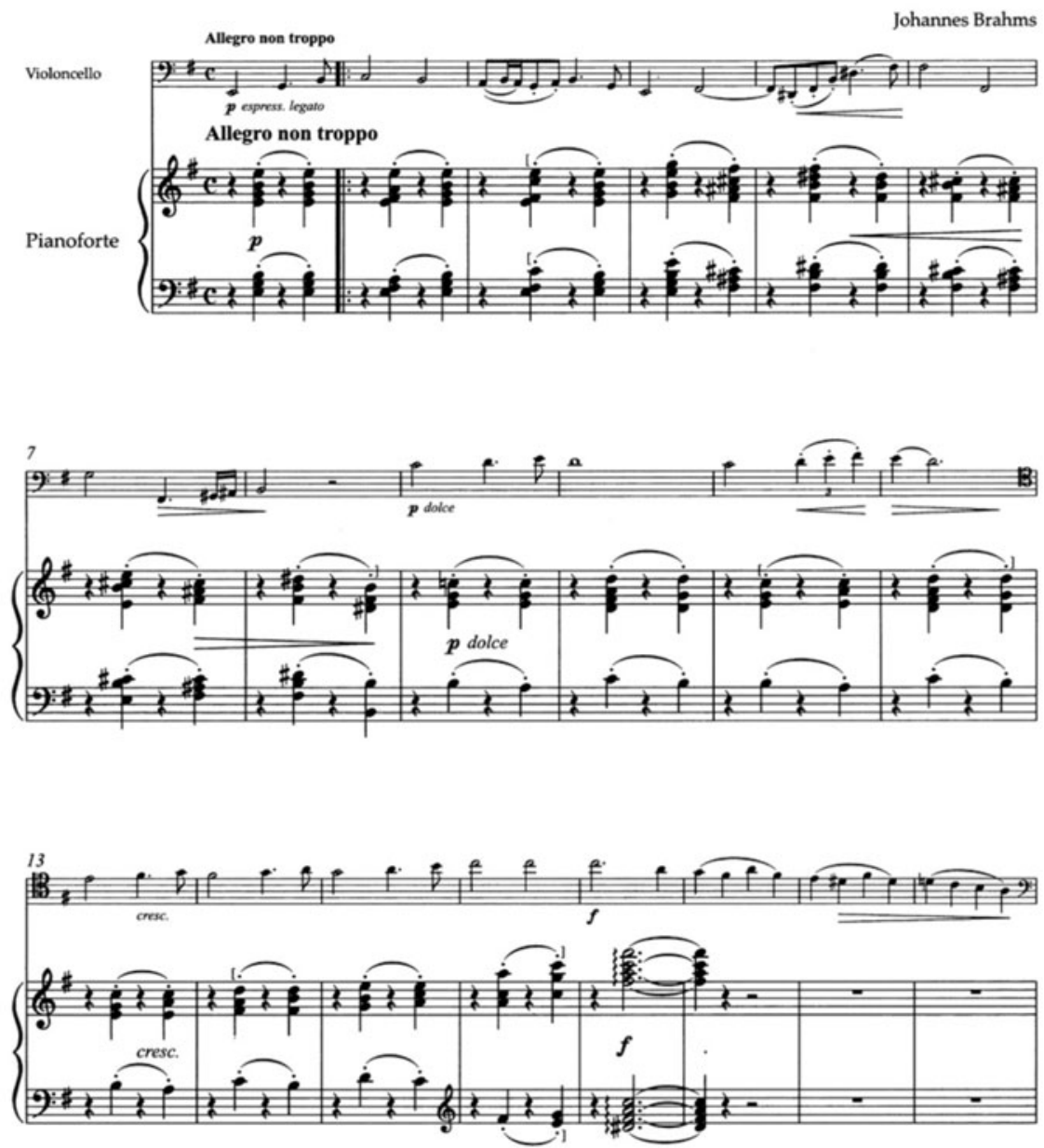

Fig. 9a Excerpt from Brahms, Sonata for Cello and Piano Op. 38, i, ed. Brown, Peres Da Costa and Bennett Wadsworth, from 'Music sample' at www.baerenreiter.com/ en/shop/product/details/BA9429: Urtext score, bars 1-20

capitalize on attributes of the digital medium that would enable musicians to engage with and make music all the more creatively. Some of those attributes have been highlighted in this article, the conclusions of which in principle could apply to music in any idiom and style, not just Western art music from the nineteenth century or indeed from any period. What is required in all cases is a more enterprising 'digital edition concept' than those underlying most of the projects

Library, London (2017): 7; https://academicbookfuture.files.wordpress.com/2017/06/project-report_academic-book-of-the-future_deegan2.pdf. 


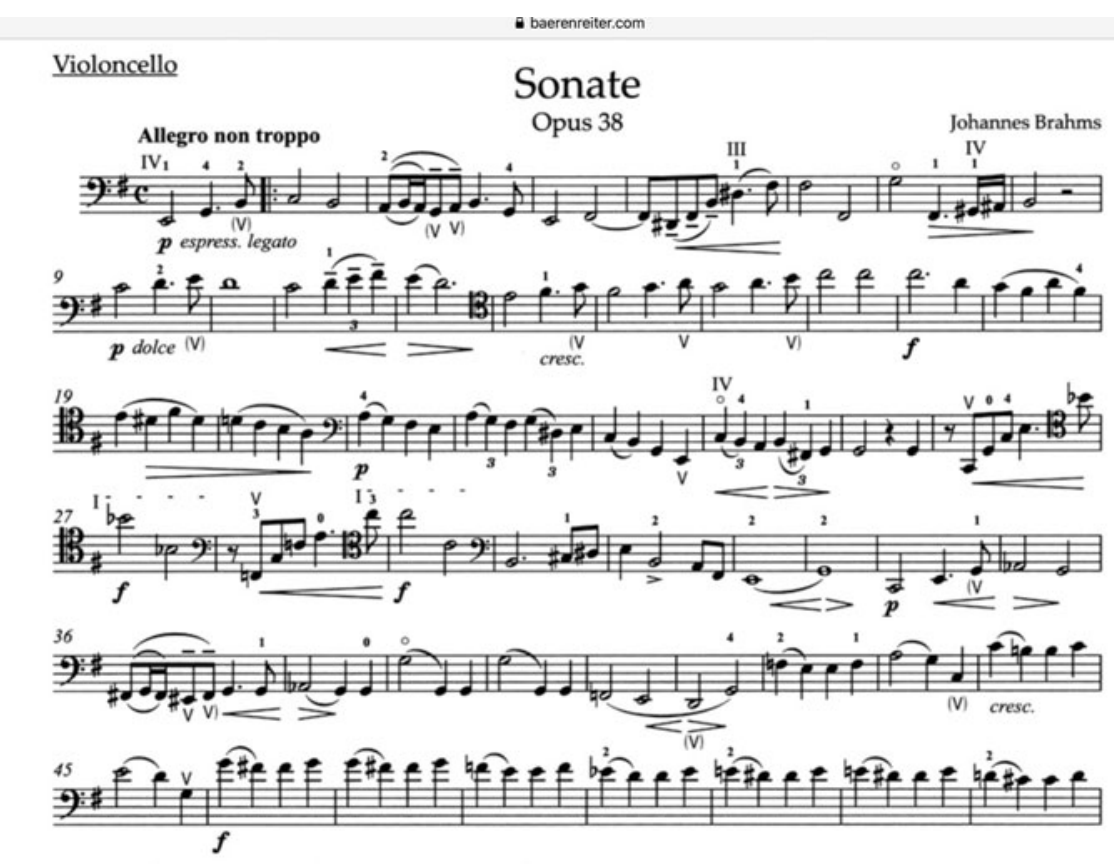

Fig. 9b Excerpt from Brahms, Sonata for Cello and Piano Op. 38, i, ed. Brown, Peres Da Costa and Bennett Wadsworth, from 'Music sample' at www.baerenreiter.com/ en/shop/product/details/BA9429: separate 'marked-up' cello part, bars 1-52

and products reviewed in the first part of the essay. Only if we move conceptually beyond the stasis of 'the material medium' and harness the dynamic flux of the digital medium can we begin to capture the dynamic flux inherent in music itself. At the same time, we must recognize and respect the need of performers to have a fixed version of the music in hand on a given occasion, even if that version is bound to be superseded either at once or over time. 